\title{
EFFECT OF ZINC AND BORON FOLIAR APPLICATION ON GROWTH, YIELD AND QUALITY OF SOME SUNFLOWER GENOTYPES ( Helianthus annuus $\mathbf{L}$.)
}

\author{
Saad A. M. Al-Doori \\ General Science Dept., College of Basic Education, Mosul University. Iraq \\ E-mail: saad35-ahmed@yahoo.com
}

\begin{abstract}
A field experiment was conducted during spring and autumn growing seasons of 2009 to study the effect of foliar application of zinc and boron on growth characters, yield components and quality of some sunflower genotypes (Helianthus annuus L.). The experiment was carried out according to the factorial experiment in a randomized completely block design, consisting of three zinc application $\left(0,6,12 \mathrm{mg} \cdot \mathrm{L}^{-1}\right)$ and three boron application $\left(0,4\right.$ and $\left.8 \mathrm{mg} \cdot \mathrm{L}^{-1}\right)$ with three sunflower genotypes (Myogen, Isaanka and Ginmus). The main findings could be summarized as follows:- Foliar application of zinc to the leaves with concentration $12 \mathrm{mg} . \mathrm{L}^{-1}$ showed a significant increase in plant height, stem diameter, leaf area, head diameter, number of seeds head $^{-1}, 1000$ seed weight and seed yield.ha ${ }^{-1}$, oil percentage, oil, protein yield (ton. $\mathrm{ha}^{-1}$ ), However, protein percent was decreased. Addition of boron sprayed on the plant leaves with concentration $4 \mathrm{mg} . \mathrm{L}^{-1}$ lead to a significant increase in plant height, stem diameter, leaf area, head diameter, number of seeds head ${ }^{-1}, 1000$ seed weight and seed yield.ha ${ }^{-1}$, oil percentage, oil, protein yield (ton.ha ${ }^{-1}$ ), while increasing concentration of boron to $8 \mathrm{mg} . \mathrm{L}^{-1}$ caused a significant increase in protein percentage in the two seasons'.

Results showed that the Isaanka genotype gave a high values for characters stem diameter, leaf area, head diameter, number of seeds. head ${ }^{-1}, 1000$ seed weight and seed yield.ha ${ }^{-1}$, oil percentage, oil, protein yield $\left(\right.$ ton.ha ${ }^{-1}$ ) in both seasons. The triple interaction among Isaanka genotype $\times$ foliar application of $12 \mathrm{mg} \mathrm{Zn} \cdot \mathrm{L}^{-1} \times$ concentration of $4 \mathrm{mg} \mathrm{B.L^{-1 }}$ sprayed on the plant leaves, achieved the highest mean for the characteristics of: plant height, stem diameter, number of seeds head ${ }^{-1}$, seed yield.ha ${ }^{-1}$ and oil, protein yield (ton.ha ${ }^{-1}$ ) for both seasons. In general, it could be concluded that for maximizing total seed and oil yields per unit area may be achieved by planting Isaanka genotype with adding zinc and boron to the leaves plant with concentration $12 \mathrm{Zn}$ and $4 \mathrm{~B} \mathrm{mg. \textrm {L } ^ { - 1 }}$ under the environmental conditions of this study.
\end{abstract}

Keywords: zinc and boron application, sunflower genotypes, Helianthus annuиs L.

Received: 1/7/2012, Accepted: 18/3/2013.

\section{INTRODUCTION}

Sunflower (Helianthus annuus L.) enjoys in having an important position in the world among the new oilseed crops, because of its quantity and high quality of edible oil. Among the factors responsible for increasing yield, judicious use of micronutrients is of prime importance. Crops require a sufficient, but not excessive, supply of essential mineral elements for optimal productivity. Insufficient supply of mineral elements may lead to limit in plant growth. In some agricultural soils, particularly in clay soil, insufficient micronutrients like zinc ( $\mathrm{Zn})$ and boron (B) are often common 
(Gitte et al, 2005). Hence, these elements can be supplied as fertilizers in both intensive and extensive agricultural systems. However, excess $\mathrm{Zn}$ and B may be toxic to plants. Increased fertilizer used efficiency can be achieved agronomically, through improved fertilizer management practices (Milutinoc and Stanojevic ,1988; 1983; Asad et al, 2002). Sunflower is one of the most sensitive crops to low zinc and boron supply, developing the characteristic of $\mathrm{Zn}, \mathrm{B}$ deficiency symptoms on leaves, stems and reproductive parts (Oyinlola, 2007).

Plants growth is significantly influenced by soil Zn, B content. It has been shown that sunflower roots are sensitive to $\mathrm{Zn}, \mathrm{B}$ deficiency as they stop their growth in less than $6 \mathrm{~h}$ after the removal of $\mathrm{Zn}, \mathrm{B}$ from the growth media (Beyersmann and Haase, 2002). Similarly, a considerable increase in dry weight of sunflower by foliar application of $28 \mathrm{mg}$ boron. $\mathrm{L}^{-1}$ has been reported (Iskander, 1993). Boron foliar application, not only increased root growth but also increased shoot dry weight of sunflower (Asad et al, 2002). Foliar applications of above mentioned mineral partially overcomes the negative effects of stress and provide plants balanced nutrients. Spray of $\mathrm{ZnSo}_{4}$ and $\mathrm{H}_{3} \mathrm{Bo}_{3}$ was better in all the vegetative growth characteristics Tahsin and Yankov, (2007) also observed a significant effect of micronutrients in growth including yield in sunflower plants by foliar application of zinc, boron and iron. Such enhancement effect of foliar application might be attributed to the favorable influence of these nutrients on metabolism and biological activity and its stimulating effect on photosynthetic pigments and enzymes activity which in turn encourage vegetative growth of plants (Milutinoc and Stanojevic, 1988). Foliar mineral spray significantly affects biomass production of plants irrespective to their growth under different soil conditions. The foliar application of above mentioned minerals appear to minimize these toxic affects through mitigating the nutrient demands of stressed plants. These minerals increased photosynthetic and enzymatic activities and an effective translocation of assimilate to reproductive parts resulting in higher yield (Lindsay, 1996). Spray of boron as an individual mineral element was found to be better in stimulating the pollen viability and germination as compared to zinc. High boron levels in the stigma and style are required for physiological inactivation of callus which is an important polysaccharide component of the pollen tube wall by the formation of borate callus complexes (Sharma et al, 1999). When boron levels are low, callus levels increase and induce the synthesis of phytoalexins including phenols which can cause an injury to membrane structure and cellular functions and bring some alteration in the morphology and structure of pollen tubes (Rani and Reddy, 1993). The aim of this research is to determine the effect of zinc and boron foliar application as well as their interactions on seed yield and its components of three sunflower genotypes under the environmental conditions of AL-Quba district, which locate near Mosul city of Iraq.

\section{MATERIALS AND METHODS}

The experiment was conducted during spring and autumn growing seasons of 2009 at AL-Quba in the west north region of Mosul city at Nineveh province, on a sandy loam soil having $33.65 \mathrm{ppm}$ available nitrogen, $10.31 \mathrm{ppm}$ available phosphorus and $153 \mathrm{ppm}$ available potassium as an average of both seasons (table 1). 
Table (1): The physical and chemical characters of soil filed experiments before planting (0 to $30 \mathrm{~cm}$ depth) in both seasons.

\begin{tabular}{|c|c|c|}
\hline Seasons & spring & autumn \\
\hline \multicolumn{2}{|c|}{ physical characters } \\
\hline Sand (\%) & 59.00 & 57.00 \\
\hline Silt (\%) & 23.00 & 32.00 \\
\hline Clay (\%) & 18.00 & 11.00 \\
\hline Texture & sandy loom & sandy loom \\
\hline \multicolumn{2}{|c|}{ chemical characters } \\
\hline Organic matter (mg.kg $\left.{ }^{-1}\right)$ & 0.82 & 0.69 \\
\hline Available N (ppm) & 33.20 & 34.10 \\
\hline Available P (ppm) & 11.20 & 9.42 \\
\hline Available K (ppm) & 164.00 & 142.00 \\
\hline Available Zn (ppm) & 4.62 & 3.46 \\
\hline Available B (ppm) & 3.60 & 2.20 \\
\hline Total CaCo $\left(\mathrm{mg}^{-1} \mathrm{~kg}^{-1}\right)$ & 2.42 & 6.4 \\
\hline pH & 7.8 & 2.00 \\
\hline E.C. $\left(\mathrm{ds.cm}{ }^{-1}\right)$ & 1.90 & \\
\hline
\end{tabular}

The experiment was laid out according to the factorial experiment in a Randomized Completely Block Design with three replications having a net plot area of $21.6 \mathrm{~m}^{2}(3.6 \mathrm{~m} \times 6.0 \mathrm{~m})$. Three levels of foliar application [0-0, 6-4 and 12-8 mg. $\mathrm{L}^{-1}$ of zinc as zinc sulphate $\left(\mathrm{ZnSo}_{4} .7 \mathrm{H}_{2} \mathrm{O} 35 \% \mathrm{Zn}\right)$ and boron as boric acid $\left(\mathrm{H}_{3} \mathrm{Bo}_{3} 17 \% \mathrm{~B}\right)$ respectively sprayed on the leaves one dose during budding stage], and three genotypes of sunflower (Myogen, Isaanka and Ginmus). The crop was sown by putting three seeds to hills by hand in $60 \mathrm{~cm}$ apart ridges, and six meters long and the distance between hills was $40 \mathrm{~cm}$ apart to attain a plant density of 41.666 plants.hectare ${ }^{-1}$ in April $1^{\text {st }}$, July $6^{\text {th }}$ and harvested in August $7^{\text {th }}$, October $26^{\text {th }}$ for spring and autumn growing seasons respectively. The plants were thinned to one plant per hill two weeks after sowing. Super phosphate $140 \mathrm{~kg}$ per hectare $\left(45 \% \mathrm{P}_{2} \mathrm{O}_{5}\right)$, and potassium $\left(48 \% \mathrm{~K}_{2} \mathrm{O}\right)$ were applied $(40 \mathrm{~kg} /$ hectare) to the soil during the sowing period, Nitrogen fertilizers was applied in the form of urea $80 \mathrm{~kg}$ hectare $(46 \% \mathrm{~N})$ in two equal doses, half with sowing and the remaining half after thinning. The first irrigation was applied immediately after sowing and after wards irrigation was scheduled at about three day's intervals. All other agronomic practices were kept normal and uniform for all the treatments. Twenty plants from each plot were selected at random to record plant height $(\mathrm{cm})$, stem diameter $(\mathrm{cm})$, leaf area $\left(\mathrm{cm}^{2}\right.$.plant), and head diameter $(\mathrm{cm})$. At harvest, ten guarded plants were taken randomly from the two inner ridges of each experimental plot and left for two weeks until fully air dried, then the following data were measured; number of seeds/head, weight of thousand seed (g.), yield and oil, protein yield (ton.ha ${ }^{-1}$ ). The seed oil content was determined by the soxholet apparatus (Anonymous, 1980), and seed nitrogen concentration was measured by microkjeldahl method, then, Protein percentage was calculated by multiplying the nitrogen percentage by the converting factor 6.25 (Agrawal et al, 1980). Concentration of zinc in soil was measured by atomic absorption spectrophotometer with wave length 213.9 nm. (Anonymous, 1998). Boron in soil was determined by atomic absorption 
spectrophotometer using curcumin and oxalic acid indicator at $540 \mathrm{~nm}$ wave length (Black, 1965, Jackson, 1973, Page et al, 1982, and Tandon, 1999). All the data were analyzed by using the SAS statistical software (Anonymous, 2001). Means were compared using Duncan's multiple range test at 1 and 5\% probability level (Duncan, 1955).

\section{RESULTS AND DISCUSSION}

1- Zinc application effect: Results of statistical analysis showed that foliar application of zinc levels significantly affected all the studied characters (table 10). Plant height, stem diameter, leaf area, head diameter, number of seeds.head ${ }^{-1}$, weight of thousand seed and seed yield.ha ${ }^{-1}$, oil percentage, oil, protein yield (ton.ha ${ }^{-1}$ ) were significantly increased as zinc application levels increased in the two seasons (table 2). The highest values of previously mentioned characters, except seed protein percentage was obtained with the highest zinc level $\left(12 \mathrm{mg} . \mathrm{L}^{-1}\right)$. Similar results were reported by others (Kathirresan et al, 2001; Cui et al, 2004; Frey et al, 2006; Mirzapour and Khoshgoftar, 2006). The increase in growth characters and yield components with the increase in zinc foliar application from 0 to $12 \mathrm{mg} . \mathrm{L}^{-1}$ might be due to the function of zinc at the cellular level of plant is to bind firmly to lamellae of chloroplast, affecting the chloroplast structure and photosynthesis (Meszaros and Simits, 1992). Seed yield $\mathrm{ha}^{-1}$ was increased from $1.588,1.544$ to $1.935,1.902$ and $2.506,2.499$ ton.ha $^{-1}$ with increasing zinc foliar application from 0 to 6 and $12 \mathrm{mg} . \mathrm{L}^{-1}$ in the two growing seasons spring and autumn respectively (table 2). These increases represent 57.80, 61.85\% respectively compared to the control. The increase in seed yield with the increase of zinc application might be due to the important role of zinc in activating the growth and yield components (Kathirresan et al, 2001). Similar results were reported by (Sharma, 2006; Tahsin and Yankov, 2007). The increase in zinc application to $12 \mathrm{mg} . \mathrm{L}^{-1}$ was associated with a decrease in seed protein percentage. Seed protein percentage decreased from 14.94, 14.16 to $12.41,11.50$ with increasing zinc application from 0 to $12 \mathrm{mg} . \mathrm{L}^{-1}$ in the two growing seasons spring and autumn respectively. The significant negative relations between seed protein content and high zinc application were also reported by (Kathirresan et al, 2001). The decrease in seed protein percentage with the increase in zinc application could be probably attributed to the sugar translocation affecting oil synthesis (table 2). Alternating enzymes imbalance could also contribute in this reduction (Sharma, 2006). Similar results were reported by others (Cui et al, 2004; Frey et al, 2006). Although the percentage of seed protein percentage decreased with the increase in zinc application to $12 \mathrm{mg} \cdot \mathrm{L}^{-1}$, the total protein yield.ha ${ }^{-1}$ significantly increased as zinc application increased up to $12 \mathrm{mg} . \mathrm{L}^{-1}$. Protein yield.ha ${ }^{-1}$ increased from $0.095,0.219$ to $0.132,0.289$ ton. $^{-1}{ }^{-1}$ with increasing zinc application from 0 to $12 \mathrm{mg} . \mathrm{L}^{-1}$, in spring and autumn seasons respectively. The increase in Protein yield with the increase in zinc application up to $12 \mathrm{mg} . \mathrm{L}^{-1}$ despite the decrease of seed protein content might be attributed to the increase in seed yield.ha ${ }^{-1}$. Similar results were reported by others (Kathirresan et al, 2001; Tahsin and Yankov, 2007).

2- Boron application effect: Concerning to the effect of boron foliar application levels on some growth characters, seed yield.ha ${ }^{-1}$ and its components, the results in table 3 indicate that growth characters, seed yield and its components were significantly affected by boron fertilizer levels in both seasons. Also, Increasing boron 
foliar application from 0 to $4 \mathrm{mg} \cdot \mathrm{L}^{-1}$ significantly increased plant height, stem diameter, leaf area, head diameter, number of seeds head ${ }^{-1}, 1000$ seed weight in both seasons. In general, increasing boron foliar application from 0 to $4 \mathrm{mg}$. $\mathrm{L}^{-1}$ increased plant height by $4.0 \%$ and $3.84 \%$, increased stem diameter by $2.42 \%$ and $3.24 \%$ and increased leaf area by $6.52 \%$ and $6.41 \%$ in spring and autumn. In addition, increasing boron foliar application from 0 to $4 \mathrm{mg} . \mathrm{L}^{-1}$ increased seed yield per hectare by $15.24 \%$ and $14.75 \%$, increased oil yield per hectare by $23.89 \%$ and $12.48 \%$ and increased protein yield per hectare by $19.00 \%$ and $21.19 \%$ in the spring and autumn seasons respectively. Increasing boron foliar application from 4 to $8 \mathrm{mg} . \mathrm{L}^{-1}$ cased decreased in the previous traits for both seasons. Table 1, also showed that the available boron in the soil is in the average of medium level which is ranged from 3.6, $3.2 \mathrm{ppm}$, and these results are in agreement with the classification of Maas (1990), although sunflower required a high quantity of boron, this reflected the response of the crop to this element when increasing the concentration from 0 to $4 \mathrm{mg} . \mathrm{L}^{-1}$. These results are in agreement with those reported by Rani and Reddy, (1993); Harris and John, (1996); Castro et al, (2000); Oyinlola, (2007). The increases in seed yield per hectare with increasing boron application dose may be attributed to the increases in head diameter, number of seeds head $^{-1}, 1000$ seed weight reflected increases of seed yield per hectare. These results are in agreement with those reported by Moore and Hirsch, (1983); Sharma et al, (1996); Asad et al, (2002). The increases in oil yield per hectare with increasing boron application dose to $4 \mathrm{mg} . \mathrm{L}^{-1}$ may be attributed to the increases in yield which reflected increases in seed yield per unit area and hence oil yield per hectare. These results are in agreement with those reported by Korenovska and Polacekova, (2000).

3- Genotypes effect: The results in table 4 indicate that sunflower genotypes significantly differed in growth characters, seed yield.ha ${ }^{-1}$ and its components in both seasons. Issanka genotype exceeded Myogen and Ginmus genotype in stem diameter, leaf area, head diameter, number of seeds. head ${ }^{-1}, 1000$ seed weight and seed yield ha ${ }^{-1}$ oil percentage, protein yield (ton.ha ${ }^{-1}$ ) in both seasons. Issanka genotype also exceeded Myogen by $15.51 \%$ and $15.84 \%$ and Ginmus genotype by $19.86 \%$ and $19.81 \%$ in seed yield per hectare in the spring and autumn seasons respectively. Myogen genotype exceeded Ginmus by $3.75 \%$ and $3.81 \%$ in yield per hectare in spring and autumn. The differences between sunflower genotypes in seed yield per hectare might be attributed to their differences in growth traits such as leaf area, head diameter that reflected differences in yield components such as number and weight of seeds head ${ }^{-1}$ as well as 1000 seed weight and hence increased seed yield per plant as well as per unit area. Similar results were obtained by many investigators such as Farah, et al, (1981); Baldini and Vear, (1994); Nel et al, (2000); Kalarani, et al, (2004); Luan, (2006); Mariayesa, et al, (2007). The increases of Issanka genotype in oil yield per hectare compared with Myogen and Ginmus genotypes may be attributed to the genetically variation among the tested genotypes in yield components and consequently seed yield as well as oil percentage. Similar results were obtained by many investigators as Dedio, (1985); Baldini and Vannozzi, (1999); Zehra et al, (2007).

4- Interaction effect of zinc and boron foliar application: The interaction between zinc and boron foliar application had a significant effect on plant height, stem diameter, leaf area, head diameter, number of seeds head ${ }^{-1}, 1000$ seed weight and seed 
yield.ha ${ }^{-1}$, oil, Protein percentage, oil, Protein yield $\left(\right.$ ton.ha $\left.^{-1}\right)$ as shown in table 5. The results indicated that addition of the highest zinc application $\left(12 \mathrm{mg} . \mathrm{L}^{-1}\right)$ with medium dose of boron $\left(4 \mathrm{mg} . \mathrm{L}^{-1}\right)$ produced the highest plant height $(154.5,152.6 \mathrm{~cm})$, stem diameter $(1.9,1.8 \mathrm{~cm})$, leaf area $\left(3396.2,3384.3 \mathrm{~cm}^{2}\right)$, head diameter $(20.9,20.8 \mathrm{~cm})$, number of seeds head ${ }^{-1}(1003.4,1002.7), 1000$ seed weight $(69.0,68.9 \mathrm{gm})$ and total seed yield $\left(2.78,2.76\right.$ ton.ha $\left.^{-1}\right)$, oil yield $\left(1.1,1.2\right.$ ton.ha $\left.^{-1}\right)$, Protein yield $(0.14,0.31$ ton.ha ${ }^{-1}$ ) in both seasons. Similar conclusions were obtained by Nel et al, (2000).

5- Interaction effect of zinc foliar application and genotypes: The interaction between zinc foliar application levels and sunflower genotypes had a significant effect on growth characters, seed yield.ha ${ }^{-1}$ and its components in both seasons as shown in table 6. The results showed that addition of the highest zinc application level i.e. 12 mg. $\mathrm{L}^{-1}$ to leaves of Issanka genotype produced maximum stem diameter, head diameter, number of seeds head ${ }^{-1}, 1000$ seed weight and seed yield ha ${ }^{-1}$ oil percentage, oil, Protein yield (ton.ha ${ }^{-1}$ ) in both seasons, which were 2.83 and 2.81 ton.ha ${ }^{-1}$ of seed yield per hectare and 1.26 and 1.27 ton per hectare of oil yield in the spring and autumn seasons respectively. The lowest seed and oil yields per a hectare were produced from sowing Ginmus genotype without adding the zinc $\left(0 \mathrm{mg} \cdot \mathrm{L}^{-1}\right)$ in both seasons. Similar results were reported by Khurana and Chatterjee, (2001); Cui et al, (2004); Frey et al, (2006); Tahsin and Yankov, (2007).

6- Interaction effect of boron foliar application and genotypes: The interaction between boron foliar application and sunflower genotypes showed significant effects on plant height, stem diameter, leaf area, head diameter, number of seeds head ${ }^{-1}, 1000$ seed weight and seed yield.ha ${ }^{-1}$, oil, protein percentage, oil, protein yield $\left(\right.$ ton.ha $\left.^{-1}\right)$ in both seasons except protein percentage and protein yield in the autumn season as illustrated in table 7. Data illustrated in table 7 show generally that Issanka, Myogen, and Ginmus genotypes appeared to be clearly affected by increasing rate of boron foliar application up to $4 \mathrm{mg} . \mathrm{L}^{-1}$ for plant height, stem diameter, leaf area and head diameter, while they appeared to be little response to $8 \mathrm{mg} \cdot \mathrm{L}^{-1}$ for those traits. On the other hand, Issanka genotype reflected the greatest response to boron foliar application up to $4 \mathrm{mg} . \mathrm{L}^{-1}$ with this regard, Remussi et al, 1972 ; Hilton and Zubriski, 1985; Meszaros and Simits, 1992; Martin et al (2007); Chhotu et al (2008); Marie and Howarth (2009) found that fertilization with $15 \mathrm{mg} . \mathrm{L}^{-1}$ produced maximum 1000 seeds weight $(53.71 \mathrm{~g})$ and seed yield $\left(4153 \mathrm{~kg} \mathrm{ha}^{-1}\right)$. The insignificant effect between genotypes and boron foliar application on other characteristic showed that each of these two factors acted independently on these traits.

7- Interaction effect of zinc, boron foliar application and genotypes: The interaction effect among the three studying factors showed significant effects on plant height, stem diameter, leaf area, head diameter, number of seeds head $^{-1}, 1000$ seed weight and seed yield.ha ${ }^{-1}$, oil, protein percentage, oil, protein yield (ton.ha ${ }^{-1}$ ) in both seasons except protein percentage in the autumn season as illustrated in tables 8 and 9 . The interaction between Issanka genotype with zinc and boron spray in concentration 4,12 mg. $\mathrm{L}^{-1}$ gave a high rate for number of seeds head ${ }^{-1}(1052.6,1054.1)$, total seed yield $\left(3.19,3.17\right.$ ton.ha $\left.^{-1}\right)$, oil percentage $(45.1,45.9 \%)$, oil yield $\left(1.44,1.45\right.$ ton.h $\left.^{-1}\right)$, protein yield $\left(0.171,0.347\right.$ ton.ha $\left.^{-1}\right)$ in both growing seasons respectively. Similar results were reported by Blamey and Chapman ,(1982); Gimenez and Fereres, (1987); 
Mesopotamia J. of Agric.

Vol. (45) No. (1) 2017
ISSN: 2224 - 9796 (Online)

ISSN: 1815 - 316 X (Print)

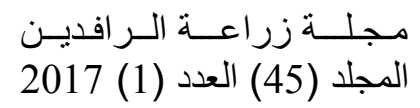

Table (2): Effect of zinc foliar application on some growth characters, yield components and quality of Sunflower in both seasons.

\begin{tabular}{|c|c|c|c|c|c|c|c|c|c|c|c|c|}
\hline seasons & $\begin{array}{c}\mathrm{Zn} \\
\text { Application } \\
\left(\mathrm{mg} \cdot \mathrm{L}^{-1}\right)\end{array}$ & $\begin{array}{l}\text { plant } \\
\text { height } \\
(\mathrm{cm}) \\
\end{array}$ & $\begin{array}{c}\text { stem } \\
\text { diameter } \\
(\mathrm{cm})\end{array}$ & $\begin{array}{l}\text { leaf area } \\
\left(\mathrm{cm}^{2} \text { plant }\right)\end{array}$ & $\begin{array}{c}\text { head } \\
\text { diameter } \\
(\mathrm{cm})\end{array}$ & $\begin{array}{c}\text { no. of } \\
\text { seeds/head }\end{array}$ & $\begin{array}{c}1000 \\
\text { seeds } \\
\text { weight(g.) }\end{array}$ & $\begin{array}{c}\text { yield } \\
\left.\text { (ton.ha }^{-1}\right)\end{array}$ & $\begin{array}{c}\text { oil } \\
(\%)\end{array}$ & $\begin{array}{l}\text { oil yield } \\
\left(\text { ton.ha }^{-1}\right)\end{array}$ & $\begin{array}{c}\text { protein } \\
(\%)\end{array}$ & $\begin{array}{c}\text { protein } \\
\text { yield } \\
\left(\text { ton.ha }^{-1}\right) \\
\end{array}$ \\
\hline \multirow{3}{*}{ spring } & 0 & $139.67 \mathrm{c}$ & $1.37 \mathrm{c}$ & $3025.31 \mathrm{c}$ & $19.81 \mathrm{c}$ & $813.36 c$ & $59.40 \mathrm{c}$ & $1.588 \mathrm{c}$ & $40.42 \mathrm{c}$ & $0.642 \mathrm{c}$ & $14.94 \mathrm{a}$ & $0.095 \mathrm{c}$ \\
\hline & 6 & $145.28 b$ & $1.60 \mathrm{~b}$ & $3294.41 b$ & $19.87 b$ & $876.70 b$ & $63.31 b$ & $1.935 b$ & $41.41 \mathrm{~b}$ & $0.802 b$ & $13.59 \mathrm{~b}$ & $0.108 b$ \\
\hline & 12 & $147.82 \mathrm{a}$ & $1.96 \mathrm{a}$ & $3355.13 \mathrm{a}$ & $20.75 a$ & $969.73 a$ & $66.30 \mathrm{a}$ & $2.506 \mathrm{a}$ & $42.62 \mathrm{a}$ & $1.070 \mathrm{a}$ & $12.41 \mathrm{c}$ & $0.132 \mathrm{a}$ \\
\hline \multirow{3}{*}{ autumn } & 0 & $137.65 \mathrm{c}$ & $1.27 \mathrm{c}$ & $3009.88 \mathrm{c}$ & $19.67 b$ & $809.32 c$ & $59.19 \mathrm{c}$ & $1.544 \mathrm{c}$ & $41.14 \mathrm{c}$ & $0.635 c$ & $14.16 \mathrm{a}$ & $0.219 \mathrm{c}$ \\
\hline & 6 & $144.21 b$ & $1.50 \mathrm{~b}$ & $3271.41 b$ & $19.71 b$ & $871.84 b$ & $62.89 \mathrm{~b}$ & $1.902 b$ & $42.13 b$ & $0.801 \mathrm{~b}$ & $12.72 b$ & $0.242 \mathrm{~b}$ \\
\hline & 12 & $146.83 \mathrm{a}$ & $1.85 \mathrm{a}$ & $3338.05 a$ & $20.67 \mathrm{a}$ & $968.28 \mathrm{a}$ & $66.21 \mathrm{a}$ & $2.499 a$ & $43.34 \mathrm{a}$ & $1.084 \mathrm{a}$ & $11.50 \mathrm{c}$ & $0.289 \mathrm{a}$ \\
\hline
\end{tabular}

${ }^{*}$ The mean values within column followed by the different letter are significant at $5 \%$ level.

Table (3): Effect of boron foliar application on some growth characters, yield components and quality of Sunflower in both seasons.

\begin{tabular}{|c|c|c|c|c|c|c|c|c|c|c|c|c|}
\hline seasons & $\begin{array}{l}\text { B Application } \\
\left(\mathrm{mg} \cdot \mathrm{L}^{-1}\right)\end{array}$ & $\begin{array}{l}\text { plant } \\
\text { height } \\
(\mathrm{cm})\end{array}$ & $\begin{array}{c}\text { stem } \\
\text { diameter } \\
(\mathrm{cm})\end{array}$ & $\begin{array}{l}\text { leaf area } \\
\left(\mathrm{cm}^{2} \text { plant }\right)\end{array}$ & $\begin{array}{l}\text { head } \\
\text { diameter } \\
(\mathrm{cm})\end{array}$ & $\begin{array}{c}\text { no. of } \\
\text { seeds/head }\end{array}$ & $\begin{array}{l}1000 \text { seeds } \\
\text { weight(g.) }\end{array}$ & $\begin{array}{c}\text { yield } \\
\left(\text { ton.ha }^{-1}\right)\end{array}$ & oil (\%) & $\begin{array}{l}\text { oil yield } \\
\text { (ton.ha }^{-1} \text { ) }\end{array}$ & $\begin{array}{l}\text { protein } \\
(\%)\end{array}$ & $\begin{array}{c}\text { protein } \\
\text { yield } \\
\left.\text { (ton.ha }{ }^{-1}\right)\end{array}$ \\
\hline \multirow{3}{*}{ spring } & 0 & $141.64 \mathrm{c}$ & $1.65 b$ & 3138.31c & $19.72 \mathrm{c}$ & $838.61 \mathrm{c}$ & $57.43 \mathrm{c}$ & $1.856 \mathrm{c}$ & $42.36 \mathrm{a}$ & $0.791 \mathrm{c}$ & $12.96 \mathrm{c}$ & $0.100 \mathrm{c}$ \\
\hline & 4 & $147.40 \mathrm{a}$ & $1.69 \mathrm{a}$ & $3342.94 a$ & $20.57 \mathrm{a}$ & $931.64 a$ & $67.87 \mathrm{a}$ & $2.132 \mathrm{a}$ & $41.39 b$ & $0.890 \mathrm{a}$ & $13.69 b$ & $0.119 a$ \\
\hline & 8 & $143.73 b$ & $1.59 \mathrm{c}$ & $3193.59 b$ & $20.14 b$ & $889.54 b$ & $63.71 b$ & $2.040 \mathrm{~b}$ & $40.70 \mathrm{c}$ & $0.834 b$ & $14.29 \mathrm{a}$ & $0.117 b$ \\
\hline \multirow{3}{*}{ autumn } & 0 & $140.36 \mathrm{c}$ & $1.54 \mathrm{~b}$ & $3123.46 c$ & $19.54 c$ & $833.82 \mathrm{c}$ & $57.15 \mathrm{c}$ & $1.833 c$ & $43.08 \mathrm{a}$ & $0.793 c$ & $12.05 \mathrm{c}$ & $0.217 b$ \\
\hline & 4 & $145.73 \mathrm{a}$ & $1.59 \mathrm{a}$ & $3323.72 \mathrm{a}$ & $20.42 \mathrm{a}$ & $928.71 \mathrm{a}$ & $67.74 a$ & $2.104 \mathrm{a}$ & $42.11 b$ & $0.892 \mathrm{a}$ & $12.76 \mathrm{~b}$ & $0.263 \mathrm{a}$ \\
\hline & 8 & $142.60 \mathrm{~b}$ & $1.49 \mathrm{c}$ & $3172.16 b$ & $20.09 b$ & $886.91 b$ & $63.40 \mathrm{~b}$ & $2.007 \mathrm{~b}$ & $41.42 \mathrm{c}$ & $0.834 b$ & $13.56 \mathrm{a}$ & $0.269 a$ \\
\hline
\end{tabular}

${ }^{*}$ The mean values within column followed by the different letters are significant at $5 \%$ level. 
Mesopotamia J. of Agric.

Vol. (45) No. (1) 2017
ISSN: 2224 - 9796 (Online) ISSN: 1815 - 316 X (Print)
مـجلــــة زر اعـــة الــر افديـن المجلد (45) العدد (1) 2017

Table (4): Effect of sunflower genotypes on some growth characters, yield components and quality in both seasons.

\begin{tabular}{|c|c|c|c|c|c|c|c|c|c|c|c|c|}
\hline seasons & genotypes & $\begin{array}{l}\text { plant } \\
\text { height } \\
(\mathrm{cm})\end{array}$ & $\begin{array}{c}\text { stem } \\
\text { diameter } \\
(\mathrm{cm})\end{array}$ & $\begin{array}{l}\text { leaf area } \\
\left(\mathrm{cm}^{2} \text { (plant) }\right.\end{array}$ & $\begin{array}{c}\text { head } \\
\text { diameter } \\
(\mathrm{cm})\end{array}$ & $\begin{array}{c}\text { no. of } \\
\text { seeds/head }\end{array}$ & $\begin{array}{c}1000 \\
\text { seeds } \\
\text { weight } \\
\text { (g.) }\end{array}$ & $\begin{array}{c}\text { yield } \\
\left(\text { ton.ha }^{-1}\right)\end{array}$ & oil (\%) & $\begin{array}{l}\text { oil yield } \\
\text { (ton.ha }^{-1} \text { ) }\end{array}$ & $\begin{array}{l}\text { protein } \\
(\%)\end{array}$ & $\begin{array}{c}\text { protein } \\
\text { yield } \\
\left.\text { (ton.ha }{ }^{-1}\right)\end{array}$ \\
\hline \multirow{3}{*}{ spring } & Myogen & $131.99 \mathrm{c}$ & $1.69 \mathrm{~b}$ & $3099.29 b$ & $20.23 b$ & $892.09 b$ & $61.82 b$ & $1.933 b$ & $40.87 b$ & $0.792 b$ & $13.75 b$ & $0.107 b$ \\
\hline & Isaanka & $144.63 b$ & $1.91 \mathrm{a}$ & 3603.39a & $21.14 \mathrm{a}$ & $936.51 \mathrm{a}$ & $67.94 a$ & $2.233 \mathrm{a}$ & $42.99 \mathrm{a}$ & $0.965 a$ & $12.70 \mathrm{c}$ & $0.120 \mathrm{a}$ \\
\hline & Ginmus & $156.15 \mathrm{a}$ & $1.32 \mathrm{c}$ & $2972.16 \mathrm{c}$ & $19.06 \mathrm{c}$ & $831.19 c$ & $59.24 c$ & $1.863 \mathrm{c}$ & $40.60 c$ & $0.757 \mathrm{c}$ & $14.49 \mathrm{a}$ & $0.108 \mathrm{c}$ \\
\hline \multirow{3}{*}{ autumn } & Myogen & $130.06 \mathrm{c}$ & $1.59 \mathrm{~b}$ & $3077.85 \mathrm{~b}$ & $20.05 b$ & $888.79 b$ & $61.62 b$ & $1.907 \mathrm{~b}$ & $41.58 b$ & $0.794 b$ & $12.88 \mathrm{~b}$ & $0.243 b$ \\
\hline & Isaanka & $146.13 b$ & $1.81 \mathrm{a}$ & $3584.46 a$ & $21.03 \mathrm{a}$ & $932.10 \mathrm{a}$ & $67.63 a$ & $2.201 \mathrm{a}$ & $43.71 \mathrm{a}$ & $0.967 \mathrm{a}$ & $11.83 \mathrm{a}$ & $0.257 \mathrm{a}$ \\
\hline & Ginmus & $152.50 \mathrm{a}$ & $1.21 \mathrm{c}$ & $2957.03 \mathrm{c}$ & $18.97 \mathrm{c}$ & $828.56 c$ & $59.04 \mathrm{c}$ & $1.837 \mathrm{c}$ & $41.32 \mathrm{c}$ & $0.759 \mathrm{c}$ & $13.67 \mathrm{c}$ & $0.248 b$ \\
\hline
\end{tabular}

${ }^{*}$ The mean values within column followed by the different letters are significant at $5 \%$ level.

Table (5): Effect of interaction between zinc and boron foliar application on some growth characters, yield components and quality in both seasons.

\begin{tabular}{|c|c|c|c|c|c|c|c|c|c|c|c|c|c|}
\hline \multirow[t]{2}{*}{ seasons } & \multicolumn{2}{|c|}{$\begin{array}{c}\text { foliar } \\
\text { Application } \\
\left(\mathrm{mg} . \mathrm{L}^{-1}\right)\end{array}$} & \multirow[t]{2}{*}{$\begin{array}{l}\text { plant } \\
\text { height } \\
(\mathrm{cm})\end{array}$} & \multirow[t]{2}{*}{$\begin{array}{l}\text { stem } \\
\text { diameter } \\
(\mathrm{cm})\end{array}$} & \multirow[t]{2}{*}{$\begin{array}{c}\text { leaf area } \\
\left(\mathrm{cm}^{2} \text { Iplant }\right)\end{array}$} & \multirow[t]{2}{*}{$\begin{array}{c}\text { head } \\
\text { diameter } \\
(\mathrm{cm})\end{array}$} & \multirow[t]{2}{*}{$\begin{array}{c}\text { no. of } \\
\text { seeds/head }\end{array}$} & \multirow[t]{2}{*}{$\begin{array}{c}1000 \\
\text { seeds } \\
\text { weight }(\mathrm{g} .)\end{array}$} & \multirow[t]{2}{*}{$\begin{array}{c}\text { yield } \\
\left(\text { ton.ha }^{-1}\right)\end{array}$} & \multirow[t]{2}{*}{$\begin{array}{l}\text { oil } \\
(\%)\end{array}$} & \multirow[t]{2}{*}{$\begin{array}{l}\text { oil yield } \\
\text { (ton.ha- }{ }^{-1} \text { ) }\end{array}$} & \multirow[t]{2}{*}{$\begin{array}{c}\text { protein } \\
(\%)\end{array}$} & \multirow[t]{2}{*}{$\begin{array}{c}\text { protein } \\
\text { yield } \\
\left.\text { (ton.ha }{ }^{-1}\right)\end{array}$} \\
\hline & zinc & boron & & & & & & & & & & & \\
\hline \multirow{5}{*}{ spring } & \multirow{3}{*}{0} & 0 & $136.86 f$ & $1.39 \mathrm{~g}$ & $2861.37 \mathrm{i}$ & $19.47 \mathrm{~g}$ & $779.85 \mathrm{i}$ & $52.13 \mathrm{~h}$ & $1.517 \mathrm{~g}$ & $41.18 \mathrm{e}$ & $0.625 \mathrm{~g}$ & $14.32 \mathrm{c}$ & $0.089 \mathrm{f}$ \\
\hline & & 4 & $140.90 \mathrm{e}$ & $1.49 \mathrm{f}$ & 3299.40f & $20.18 d$ & $844.02 f$ & $66.77 \mathrm{c}$ & $1.638 \mathrm{f}$ & $40.21 \mathrm{~g}$ & $0.660 f$ & $15.03 b$ & $0.098 \mathrm{e}$ \\
\hline & & 8 & $141.24 \mathrm{e}$ & $1.23 \mathrm{~h}$ & $2915.15 \mathrm{~h}$ & $19.78 \mathrm{f}$ & $816.22 \mathrm{~g}$ & $59.29 f$ & $1.610 \mathrm{f}$ & $39.88 \mathrm{~h}$ & $0.642 \mathrm{fg}$ & $15.47 \mathrm{a}$ & $0.098 \mathrm{e}$ \\
\hline & \multirow[b]{2}{*}{6} & 0 & $142.62 d$ & $1.65 \mathrm{c}$ & $3242.08 \mathrm{~g}$ & $18.96 \mathrm{~h}$ & $785.08 \mathrm{~h}$ & $57.75 \mathrm{~g}$ & $1.895 \mathrm{e}$ & $42.19 c$ & 0.800de & $13.06 \mathrm{e}$ & $0.104 d$ \\
\hline & & 4 & $146.79 b$ & $1.59 \mathrm{~d}$ & $3333.18 c$ & $20.58 c$ & $947.46 \mathrm{~d}$ & $67.81 \mathrm{~b}$ & $1.980 \mathrm{~d}$ & $41.33 \mathrm{ed}$ & $0.819 \mathrm{~d}$ & $13.51 \mathrm{~d}$ & $0.110 \mathrm{c}$ \\
\hline
\end{tabular}


Mesopotamia J. of Agric.

Vol. (45) No. (1) 2017
ISSN: $2224-9796$ (Online) ISSN: 1815 - 316 X (Print)

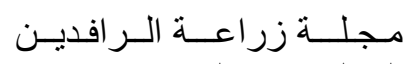
المجلد (45) العدد (1) 2017

\begin{tabular}{|c|c|c|c|c|c|c|c|c|c|c|c|c|c|}
\hline \multirow[t]{6}{*}{ seasons } & \multicolumn{2}{|c|}{$\begin{array}{c}\text { foliar } \\
\text { Application } \\
\left(\mathrm{mg} . \mathrm{L}^{-1}\right)\end{array}$} & \multirow[t]{2}{*}{$\begin{array}{l}\text { plant } \\
\text { height } \\
(\mathrm{cm})\end{array}$} & \multirow[t]{2}{*}{$\begin{array}{c}\text { stem } \\
\text { diameter } \\
(\mathrm{cm})\end{array}$} & \multirow[t]{2}{*}{$\begin{array}{c}\text { leaf area } \\
\left(\mathrm{cm}^{2} \text { |plant }\right)\end{array}$} & \multirow[t]{2}{*}{$\begin{array}{l}\text { head } \\
\text { diameter } \\
(\mathrm{cm})\end{array}$} & \multirow[t]{2}{*}{$\begin{array}{c}\text { no. of } \\
\text { seeds/head }\end{array}$} & \multirow[t]{2}{*}{$\begin{array}{c}1000 \\
\text { seeds } \\
\text { weight(g.) }\end{array}$} & \multirow[t]{2}{*}{$\begin{array}{c}\text { yield } \\
\left(\text { ton.ha }^{-1}\right)\end{array}$} & \multirow[t]{2}{*}{$\begin{array}{l}\text { oil } \\
(\%)\end{array}$} & \multirow[t]{2}{*}{$\begin{array}{l}\text { oil yield } \\
\left(\text { ton.ha }^{-1}\right)\end{array}$} & \multirow[t]{2}{*}{$\begin{array}{l}\text { protein } \\
(\%)\end{array}$} & \multirow[t]{2}{*}{$\begin{array}{c}\text { protein } \\
\text { yield } \\
\text { (ton.ha }^{-1} \text { ) }\end{array}$} \\
\hline & zinc & boron & & & & & & & & & & & \\
\hline & & 8 & $146.42 b c$ & $1.57 \mathrm{e}$ & $3307.97 \mathrm{e}$ & $20.07 \mathrm{e}$ & $897.57 \mathrm{e}$ & $64.37 d$ & $1.930 \mathrm{de}$ & $40.71 \mathrm{f}$ & $0.786 \mathrm{e}$ & $14.20 \mathrm{c}$ & $0.111 \mathrm{c}$ \\
\hline & \multirow{3}{*}{12} & 0 & $145.44 \mathrm{c}$ & $1.90 \mathrm{~b}$ & $3311.49 d$ & $20.73 b$ & $950.90 \mathrm{c}$ & $62.40 \mathrm{e}$ & $2.156 \mathrm{c}$ & $43.71 \mathrm{a}$ & $0.946 \mathrm{c}$ & $11.50 \mathrm{~g}$ & $0.108 \mathrm{c}$ \\
\hline & & 4 & $154.51 \mathrm{a}$ & $1.99 \mathrm{a}$ & $3396.23 a$ & $20.95 a$ & $1003.45 \mathrm{a}$ & $69.03 \mathrm{a}$ & $2.780 \mathrm{a}$ & $42.64 b$ & $1.190 \mathrm{a}$ & $12.53 \mathrm{f}$ & $0.148 \mathrm{a}$ \\
\hline & & 8 & $143.53 \mathrm{~d}$ & $1.98 \mathrm{a}$ & $3357.65 b$ & $20.57 \mathrm{c}$ & $954.85 b$ & $67.47 \mathrm{~b}$ & $2.582 b$ & $41.51 \mathrm{~d}$ & $1.074 \mathrm{~b}$ & $13.19 \mathrm{e}$ & $0.141 b$ \\
\hline \multirow{9}{*}{ autumn } & \multirow{3}{*}{0} & 0 & $135.23 \mathrm{e}$ & $1.29 \mathrm{~g}$ & $2860.59 \mathrm{~g}$ & $19.34 \mathrm{e}$ & $775.81 \mathrm{~g}$ & $51.82 \mathrm{~h}$ & $1.47 \mathrm{~h}$ & $41.90 f$ & $0.617 \mathrm{i}$ & $13.63 b$ & $0.201 \mathrm{e}$ \\
\hline & & 4 & 138.71de & $1.39 \mathrm{f}$ & $3276.62 d$ & $20.03 c$ & $841.08 \mathrm{e}$ & $66.90 \mathrm{c}$ & $1.59 \mathrm{~g}$ & $40.93 \mathrm{~h}$ & $0.652 \mathrm{~g}$ & $14.29 \mathrm{a}$ & $0.228 \mathrm{~d}$ \\
\hline & & 8 & $139.01 \mathrm{de}$ & $1.13 \mathrm{~h}$ & $2892.43 f$ & $19.63 d$ & $811.06 f$ & $58.86 f$ & $1.56 \mathrm{~g}$ & $40.63 \mathrm{i}$ & $0.635 \mathrm{~h}$ & $14.56 \mathrm{a}$ & $0.227 d$ \\
\hline & \multirow{3}{*}{6} & 0 & $140.17 \mathrm{~d}$ & $1.55 \mathrm{~d}$ & $3219.08 \mathrm{e}$ & $18.80 \mathrm{f}$ & $779.93 \mathrm{~g}$ & $57.32 \mathrm{~g}$ & $1.86 \mathrm{f}$ & 42.91c & $0.799 \mathrm{e}$ & $12.04 \mathrm{~d}$ & $0.224 d$ \\
\hline & & 4 & $145.87 b c$ & $1.48 \mathrm{e}$ & $3310.18 c$ & $20.43 b$ & $942.30 \mathrm{c}$ & $67.39 b$ & $1.95 \mathrm{~d}$ & $42.05 \mathrm{e}$ & $0.821 d$ & $12.49 \mathrm{c}$ & $0.243 c$ \\
\hline & & 8 & $146.60 b$ & $1.47 \mathrm{e}$ & $3284.97 d$ & $19.88 \mathrm{~cd}$ & $893.31 d$ & $63.95 d$ & $1.89 \mathrm{e}$ & $41.43 \mathrm{~g}$ & $0.785 f$ & $13.63 b$ & $0.258 \mathrm{~b}$ \\
\hline & \multirow{3}{*}{12} & 0 & $145.70 b c$ & $1.80 \mathrm{c}$ & $3290.72 d$ & $20.47 b$ & $945.74 c$ & $62.31 \mathrm{e}$ & $2.16 \mathrm{c}$ & $44.43 \mathrm{a}$ & $0.965 \mathrm{c}$ & $10.48 f$ & $0.227 d$ \\
\hline & & 4 & $152.61 \mathrm{a}$ & $1.89 \mathrm{a}$ & $3384.34 \mathrm{a}$ & $20.80 \mathrm{a}$ & $1002.74 a$ & $68.94 a$ & $2.76 \mathrm{a}$ & $43.36 b$ & $1.204 \mathrm{a}$ & $11.51 \mathrm{e}$ & $0.318 \mathrm{a}$ \\
\hline & & 8 & $142.19 \mathrm{~cd}$ & $1.87 \mathrm{~b}$ & $3339.10 b$ & $20.75 a$ & $956.35 b$ & $67.38 b$ & $2.56 \mathrm{~b}$ & $42.25 d$ & $1.083 b$ & $12.50 \mathrm{c}$ & $0.321 \mathrm{a}$ \\
\hline
\end{tabular}

* The mean values within column followed by the different letters are significant at $5 \%$ level. 
Mesopotamia J. of Agric.

Vol. (45) No. (1) 2017
ISSN: 2224 - 9796 (Online)

ISSN: 1815 - 316 X (Print)

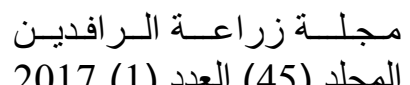
المجلد (45) العدد (1) 2017

Table (6): Effect of interaction between zinc foliar application and sunflower genotypes on some growth characters, yield components and quality in both seasons.

\begin{tabular}{|c|c|c|c|c|c|c|c|c|c|c|c|c|c|}
\hline seasons & $\mathrm{Zn}$ & genotypes & $\begin{array}{l}\text { plant } \\
\text { height } \\
(\mathrm{cm})\end{array}$ & $\begin{array}{c}\text { stem } \\
\text { diameter } \\
(\mathrm{cm})\end{array}$ & $\begin{array}{c}\text { leaf area } \\
\left(\mathrm{cm}^{2} \text { Iplant }\right)\end{array}$ & $\begin{array}{l}\text { head } \\
\text { diameter } \\
(\mathrm{cm})\end{array}$ & $\begin{array}{c}\text { no. of } \\
\text { seeds/head }\end{array}$ & $\begin{array}{c}1000 \\
\text { seeds } \\
\text { weight } \\
\text { (g.) }\end{array}$ & $\begin{array}{c}\text { yield } \\
\left(\text { ton.ha }^{-1}\right)\end{array}$ & $\begin{array}{l}\text { oil } \\
(\%)\end{array}$ & $\begin{array}{l}\text { oil yield } \\
\text { (ton.ha }^{-1} \text { ) }\end{array}$ & $\begin{array}{c}\text { protein } \\
(\%)\end{array}$ & $\begin{array}{c}\text { protein } \\
\text { yield } \\
\left(\text { ton.ha }^{-1}\right)\end{array}$ \\
\hline \multirow{9}{*}{ spring } & \multirow{3}{*}{0} & Myogen & $129.80 \mathrm{i}$ & $1.33 \mathrm{f}$ & $2828.94 \mathrm{~h}$ & $19.65 \mathrm{~g}$ & $815.77 \mathrm{~h}$ & $57.23 \mathrm{~g}$ & $1.548 \mathrm{~h}$ & $39.85 \mathrm{~h}$ & $0.617 \mathrm{~h}$ & $15.04 b$ & $0.092 \mathrm{f}$ \\
\hline & & Isaanka & 138.60f & $1.73 \mathrm{e}$ & $3479.26 c$ & $20.73 d$ & $857.34 f$ & $65.15 d$ & $1.715 \mathrm{~g}$ & $41.71 d$ & $0.715 \mathrm{~g}$ & $13.69 d$ & $0.097 \mathrm{e}$ \\
\hline & & Ginmus & $150.60 d$ & $1.06 \mathrm{~h}$ & $2767.72 \mathrm{i}$ & $19.05 \mathrm{~h}$ & $766.98 \mathrm{i}$ & $55.81 \mathrm{~h}$ & $1.502 \mathrm{i}$ & $39.72 \mathrm{i}$ & $0.596 \mathrm{i}$ & $16.08 \mathrm{a}$ & $0.096 \mathrm{e}$ \\
\hline & \multirow{3}{*}{6} & Myogen & 132.40h & $1.77 \mathrm{~d}$ & $3132.48 f$ & $20.14 \mathrm{e}$ & $879.69 \mathrm{e}$ & $61.80 \mathrm{e}$ & $1.858 \mathrm{e}$ & $40.83 \mathrm{~g}$ & $0.758 \mathrm{e}$ & $13.72 d$ & $0.104 d$ \\
\hline & & Isaanka & $143.70 \mathrm{e}$ & $1.89 \mathrm{c}$ & $3788.04 a$ & $21.10 \mathrm{~b}$ & $929.27 \mathrm{c}$ & $67.76 b$ & $2.148 d$ & $42.55 b$ & $0.913 d$ & $12.72 \mathrm{f}$ & $0.116 c$ \\
\hline & & Ginmus & $159.70 \mathrm{a}$ & $1.16 \mathrm{~g}$ & $2962.70 \mathrm{~g}$ & $18.36 \mathrm{i}$ & $821.15 \mathrm{~g}$ & $60.37 f$ & $1.797 \mathrm{f}$ & $40.87 f$ & $0.734 \mathrm{f}$ & $14.33 \mathrm{c}$ & $0.105 d$ \\
\hline & \multirow{3}{*}{12} & Myogen & $133.80 \mathrm{~g}$ & $1.98 \mathrm{~b}$ & $3336.46 \mathrm{~d}$ & $20.89 c$ & $980.82 b$ & $66.44 \mathrm{c}$ & $2.392 b$ & $41.93 \mathrm{c}$ & $1.000 \mathrm{~b}$ & $12.49 \mathrm{~g}$ & $0.125 b$ \\
\hline & & Isaanka & $151.60 \mathrm{c}$ & $2.13 a$ & $3542.87 \mathrm{~b}$ & $21.60 \mathrm{a}$ & $1022.93 \mathrm{a}$ & $70.92 \mathrm{a}$ & $2.836 \mathrm{a}$ & $44.73 a$ & $1.269 \mathrm{a}$ & $11.68 \mathrm{~h}$ & $0.148 \mathrm{a}$ \\
\hline & & Ginmus & $158.10 \mathrm{~b}$ & $1.76 \mathrm{~d}$ & $3186.05 \mathrm{e}$ & $19.77 \mathrm{f}$ & $905.45 d$ & $61.55 \mathrm{e}$ & $2.290 \mathrm{c}$ & $41.21 \mathrm{e}$ & $0.941 \mathrm{c}$ & $13.05 \mathrm{e}$ & $0.123 b$ \\
\hline \multirow{9}{*}{ autumn } & \multirow{3}{*}{0} & Myogen & $128.01 \mathrm{~h}$ & $1.22 \mathrm{~g}$ & $2806.00 \mathrm{~h}$ & $19.53 \mathrm{~g}$ & $813.00 \mathrm{~h}$ & $57.14 \mathrm{~h}$ & $1.504 \mathrm{~h}$ & $40.57 \mathrm{~h}$ & $0.610 \mathrm{~h}$ & $14.25 b$ & $0.215 \mathrm{i}$ \\
\hline & & Isaanka & $139.94 \mathrm{e}$ & $1.63 \mathrm{f}$ & $3467.00 \mathrm{c}$ & $20.59 d$ & $852.00 f$ & $64.73 d$ & $1.671 \mathrm{~g}$ & $42.43 d$ & $0.708 \mathrm{~g}$ & $12.90 \mathrm{~d}$ & $0.216 \mathrm{~h}$ \\
\hline & & Ginmus & $145.00 \mathrm{~d}$ & $0.95 \mathrm{i}$ & $2756.00 \mathrm{i}$ & $18.90 \mathrm{~h}$ & $763.00 \mathrm{i}$ & $55.72 \mathrm{i}$ & $1.458 \mathrm{i}$ & $40.44 \mathrm{i}$ & $0.588 \mathrm{i}$ & $15.35 \mathrm{a}$ & $0.225 \mathrm{~g}$ \\
\hline & \multirow{3}{*}{6} & Myogen & $130.32 \mathrm{~g}$ & $1.66 \mathrm{~d}$ & $3109.00 f$ & $20.00 \mathrm{e}$ & $875.00 \mathrm{e}$ & $61.38 f$ & $1.825 \mathrm{e}$ & $41.54 \mathrm{~g}$ & $0.758 \mathrm{e}$ & $12.82 \mathrm{e}$ & $0.235 f$ \\
\hline & & Isaanka & $144.84 d$ & $1.78 \mathrm{c}$ & $3765.00 \mathrm{a}$ & $20.95 b$ & $924.00 \mathrm{c}$ & $67.35 b$ & $2.119 \mathrm{~d}$ & $43.26 b$ & $0.915 \mathrm{~d}$ & $11.82 \mathrm{~g}$ & $0.251 \mathrm{~d}$ \\
\hline & & Ginmus & $157.48 \mathrm{a}$ & $1.05 \mathrm{~h}$ & $2940.00 \mathrm{~g}$ & $18.18 \mathrm{i}$ & $817.00 \mathrm{~g}$ & $59.95 \mathrm{~g}$ & $1.763 \mathrm{f}$ & $41.59 f$ & $0.733 \mathrm{f}$ & $13.54 \mathrm{c}$ & $0.239 \mathrm{e}$ \\
\hline & \multirow{3}{*}{12} & Myogen & $131.84 \mathrm{f}$ & $1.88 \mathrm{~b}$ & $3318.00 \mathrm{~d}$ & $20.63 c$ & $979.00 \mathrm{~b}$ & $66.35 c$ & $2.392 b$ & $42.65 c$ & $1.017 \mathrm{~b}$ & $11.58 \mathrm{~h}$ & $0.280 \mathrm{c}$ \\
\hline & & Isaanka & $153.63 \mathrm{c}$ & $2.03 a$ & $3521.00 \mathrm{~b}$ & $21.56 \mathrm{a}$ & $1020.00 \mathrm{a}$ & $70.83 a$ & $2.814 \mathrm{a}$ & $45.45 \mathrm{a}$ & $1.279 \mathrm{a}$ & $10.78 \mathrm{i}$ & $0.305 a$ \\
\hline & & Ginmus & $155.03 \mathrm{~b}$ & $1.65 \mathrm{e}$ & $3175.00 \mathrm{e}$ & $19.84 f$ & $906.00 \mathrm{~d}$ & $61.46 \mathrm{e}$ & $2.293 c$ & $41.94 \mathrm{e}$ & $0.959 \mathrm{c}$ & $12.14 \mathrm{f}$ & $0.281 b$ \\
\hline
\end{tabular}

${ }^{*}$ The mean values within column followed by the different letters are significant at $5 \%$ level. 
Mesopotamia J. of Agric.

Vol. (45) No. (1) 2017
ISSN: 2224 - 9796 (Online)

ISSN: 1815 - 316 X (Print)

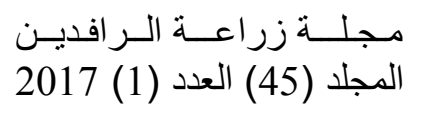

Table (7): Effect of interaction between boron foliar application and sunflower genotypes on some growth characters, yield components and quality in both seasons.

\begin{tabular}{|c|c|c|c|c|c|c|c|c|c|c|c|c|c|}
\hline seasons & B & genotypes & $\begin{array}{l}\text { plant } \\
\text { height } \\
(\mathrm{cm})\end{array}$ & $\begin{array}{c}\text { stem } \\
\text { diameter } \\
(\mathrm{cm})\end{array}$ & $\begin{array}{l}\text { leaf area } \\
\left(\mathrm{cm}^{2} \text { plant }\right)\end{array}$ & $\begin{array}{l}\text { head } \\
\text { diameter } \\
(\mathrm{cm})\end{array}$ & $\begin{array}{c}\text { no. of } \\
\text { seeds/head }\end{array}$ & $\begin{array}{c}1000 \\
\text { seeds } \\
\text { weight } \\
\text { (g.) }\end{array}$ & $\begin{array}{c}\text { yield } \\
\left(\text { ton.ha }^{-1}\right)\end{array}$ & $\begin{array}{c}\text { oil } \\
(\%)\end{array}$ & $\begin{array}{l}\text { oil yield } \\
\left(\text { ton.ha }^{-1}\right)\end{array}$ & $\begin{array}{l}\text { protein } \\
(\%)\end{array}$ & $\begin{array}{c}\text { protein } \\
\text { yield } \\
\left.\text { (ton.ha }{ }^{-1}\right)\end{array}$ \\
\hline \multirow{9}{*}{ spring } & \multirow{3}{*}{0} & Myogen & $129.15 \mathrm{~h}$ & $1.68 \mathrm{e}$ & $3042.19 f$ & $19.66 f$ & $843.44 \mathrm{~g}$ & $56.07 \mathrm{~g}$ & $1.784 \mathrm{~g}$ & $41.58 \mathrm{~d}$ & $0.743 \mathrm{f}$ & $13.05 \mathrm{f}$ & $0.096 \mathrm{e}$ \\
\hline & & Isaanka & 139.26f & $1.91 \mathrm{~b}$ & $3443.27 c$ & $20.74 \mathrm{c}$ & $890.79 \mathrm{e}$ & $61.33 \mathrm{e}$ & $2.074 \mathrm{c}$ & $43.97 \mathrm{a}$ & $0.916 \mathrm{c}$ & $12.09 \mathrm{~h}$ & $0.108 \mathrm{~d}$ \\
\hline & & Ginmus & $156.50 \mathrm{~b}$ & $1.36 \mathrm{f}$ & $2929.49 \mathrm{i}$ & $18.76 \mathrm{i}$ & $781.60 \mathrm{i}$ & $54.88 \mathrm{~h}$ & $1.711 \mathrm{~h}$ & $41.53 d$ & $0.712 \mathrm{~g}$ & $13.74 d$ & $0.096 \mathrm{e}$ \\
\hline & \multirow{3}{*}{4} & Myogen & $133.06 \mathrm{~g}$ & $1.72 \mathrm{~d}$ & $3146.75 d$ & $20.59 d$ & $932.43 c$ & $66.48 \mathrm{c}$ & $2.030 \mathrm{~cd}$ & $40.58 \mathrm{e}$ & $0.827 \mathrm{~d}$ & $13.74 d$ & $0.111 \mathrm{~cd}$ \\
\hline & & Isaanka & $150.35 d$ & $2.02 \mathrm{a}$ & $3872.03 \mathrm{a}$ & $21.53 \mathrm{a}$ & $983.71 \mathrm{a}$ & $74.10 \mathrm{a}$ & $2.398 \mathrm{a}$ & $43.10 b$ & $1.042 \mathrm{a}$ & $12.72 \mathrm{~g}$ & $0.130 \mathrm{a}$ \\
\hline & & Ginmus & $158.79 \mathrm{a}$ & $1.32 \mathrm{~g}$ & $3010.03 \mathrm{~g}$ & $19.59 \mathrm{~g}$ & $878.79 f$ & $63.04 d$ & $1.970 \mathrm{e}$ & $40.50 \mathrm{e}$ & $0.800 \mathrm{e}$ & $14.60 \mathrm{~b}$ & $0.114 \mathrm{c}$ \\
\hline & \multirow{3}{*}{8} & Myogen & $133.75 \mathrm{~g}$ & $1.68 \mathrm{e}$ & $3108.94 \mathrm{e}$ & $20.43 \mathrm{e}$ & $900.41 d$ & $62.91 d$ & $1.985 \mathrm{de}$ & $40.44 \mathrm{e}$ & $0.805 \mathrm{de}$ & $14.45 \mathrm{c}$ & $0.114 \mathrm{c}$ \\
\hline & & Isaanka & $144.28 \mathrm{e}$ & $1.81 \mathrm{c}$ & $3494.87 b$ & $21.16 \mathrm{~b}$ & $935.04 b$ & $68.41 b$ & $2.227 \mathrm{~b}$ & $41.91 \mathrm{c}$ & $0.938 b$ & $13.28 \mathrm{e}$ & $0.123 b$ \\
\hline & & Ginmus & $153.15 \mathrm{c}$ & $1.29 \mathrm{~h}$ & 2976.96h & $18.83 \mathrm{~h}$ & $833.19 \mathrm{~h}$ & $59.81 \mathrm{f}$ & $1.908 \mathrm{f}$ & $39.75 \mathrm{f}$ & $0.759 \mathrm{f}$ & $15.12 \mathrm{a}$ & $0.113 c$ \\
\hline \multirow{9}{*}{ autumn } & \multirow{3}{*}{0} & Myogen & $127.19 \mathrm{f}$ & $1.58 \mathrm{e}$ & $3019.19 f$ & $19.43 \mathrm{e}$ & $838.28 f$ & $55.76 \mathrm{~g}$ & $1.76 \mathrm{~g}$ & $42.30 \mathrm{~d}$ & $0.748 \mathrm{f}$ & 12.15 & 0.213 \\
\hline & & Isaanka & $141.74 d$ & $1.80 \mathrm{~b}$ & $3432.49 c$ & $20.58 \mathrm{c}$ & $885.64 d$ & $61.01 \mathrm{e}$ & $2.04 \mathrm{c}$ & $44.69 a$ & $0.917 \mathrm{c}$ & 11.18 & 0.225 \\
\hline & & Ginmus & $152.17 \mathrm{ab}$ & $1.25 \mathrm{f}$ & $2918.71 \mathrm{i}$ & $18.61 \mathrm{~g}$ & $777.55 \mathrm{~h}$ & $54.68 \mathrm{~h}$ & $1.68 \mathrm{~h}$ & $42.25 \mathrm{e}$ & $0.715 \mathrm{~g}$ & 12.83 & 0.214 \\
\hline & \multirow{3}{*}{4} & Myogen & $131.31 \mathrm{e}$ & $1.61 \mathrm{~d}$ & $3123.97 \mathrm{~d}$ & $20.44 \mathrm{~cd}$ & $929.49 b$ & $66.50 \mathrm{c}$ & $1.99 \mathrm{~d}$ & 41.30f & $0.828 \mathrm{~d}$ & 12.83 & 0.252 \\
\hline & & Isaanka & $150.53 b$ & $1.94 \mathrm{a}$ & $3849.03 a$ & $21.39 \mathrm{a}$ & $980.77 \mathrm{a}$ & $73.78 \mathrm{a}$ & $2.37 \mathrm{a}$ & $43.81 b$ & $1.047 \mathrm{a}$ & 11.81 & 0.276 \\
\hline & & Ginmus & $155.35 \mathrm{a}$ & $1.21 \mathrm{~g}$ & $2998.14 \mathrm{~g}$ & $19.43 \mathrm{e}$ & $875.86 \mathrm{e}$ & $62.95 \mathrm{~d}$ & $1.94 \mathrm{e}$ & $41.22 \mathrm{~g}$ & $0.803 \mathrm{e}$ & 13.64 & 0.261 \\
\hline & \multirow{3}{*}{8} & Myogen & $131.67 \mathrm{e}$ & $1.58 \mathrm{e}$ & $3090.38 \mathrm{e}$ & $20.27 d$ & $898.58 c$ & $62.60 d$ & $1.95 \mathrm{e}$ & $41.15 \mathrm{~h}$ & $0.807 \mathrm{e}$ & 13.66 & 0.265 \\
\hline & & Isaanka & $146.13 \mathrm{c}$ & $1.71 \mathrm{c}$ & $3471.87 b$ & $21.12 b$ & $929.88 b$ & $68.10 \mathrm{~b}$ & $2.18 b$ & $42.63 c$ & $0.936 b$ & 12.49 & 0.271 \\
\hline & & Ginmus & $150.00 \mathrm{bc}$ & $1.18 \mathrm{~h}$ & $2954.25 \mathrm{~h}$ & $18.87 f$ & $832.26 \mathrm{~g}$ & $59.49 \mathrm{f}$ & $1.88 \mathrm{f}$ & $40.49 \mathrm{i}$ & $0.761 \mathrm{f}$ & 14.54 & 0.270 \\
\hline
\end{tabular}

${ }^{*}$ The mean values within column followed by the different letters are significant at $5 \%$ level. 
Mesopotamia J. of Agric.

Vol. (45) No. (1) 2017
ISSN: 2224 - 9796 (Online)

ISSN: 1815 - 316 X (Print)

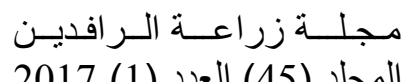
المجلد (45) العدد (1) 2017

Table (8): Effect of interaction between zinc, boron foliar application and sunflower genotypes on some growth characters, yield components and quality in spring seasons.

\begin{tabular}{|c|c|c|c|c|c|c|c|c|c|c|c|c|c|}
\hline \multicolumn{2}{|c|}{$\begin{array}{c}\text { Application } \\
\left(\mathrm{mg} \cdot \mathrm{L}^{-1}\right)\end{array}$} & \multirow[t]{2}{*}{ genotypes } & \multirow{2}{*}{$\begin{array}{l}\text { plant } \\
\text { height } \\
(\mathrm{cm}) \\
\end{array}$} & \multirow{2}{*}{$\begin{array}{c}\text { stem } \\
\text { diameter } \\
(\mathrm{cm}) \\
\end{array}$} & \multirow[t]{2}{*}{$\begin{array}{l}\text { leaf area } \\
\left(\mathrm{cm}^{2} \text { plant }\right)\end{array}$} & \multirow{2}{*}{$\begin{array}{c}\text { head } \\
\text { diameter } \\
(\mathrm{cm})\end{array}$} & \multirow[t]{2}{*}{$\begin{array}{c}\text { no. of } \\
\text { seeds/head }\end{array}$} & \multirow{2}{*}{$\begin{array}{c}1000 \\
\text { seeds } \\
\text { weight(g.) }\end{array}$} & \multirow{2}{*}{$\begin{array}{c}\text { yield } \\
\text { (ton.ha } \\
1 \\
\text { ( })\end{array}$} & \multirow[t]{2}{*}{$\begin{array}{c}\text { oil } \\
(\%)\end{array}$} & \multirow[t]{2}{*}{$\begin{array}{l}\text { oil yield } \\
\text { (ton.ha }^{-1} \text { ) }\end{array}$} & \multirow[t]{2}{*}{$\begin{array}{l}\text { protein } \\
(\%)\end{array}$} & \multirow{2}{*}{$\begin{array}{c}\text { protein } \\
\text { yield } \\
\left(\text { ton.ha }^{-1}\right)\end{array}$} \\
\hline zinc & boron & & & & & & & & & & & & \\
\hline \multirow{9}{*}{0} & \multirow{3}{*}{0} & Myogen & $125.73 n$ & $1.38 \mathrm{k}$ & $2772.17 y$ & 19.371 & $769.12 \mathrm{w}$ & $50.68 \mathrm{p}$ & 1.5261 & 40.42hi & 0.6171 & $14.32 \mathrm{~d}$ & $0.088 n$ \\
\hline & & Isaanka & $135.06 \mathrm{ij}$ & $1.77 \mathrm{~h}$ & $3098.75 q$ & $20.54 \mathrm{~g}$ & $830.19 q$ & 54.660 & 1.6231 & $42.73 d$ & $0.693 \mathrm{k}$ & $13.13 \mathrm{~h}$ & $0.091 \mathrm{mn}$ \\
\hline & & Ginmus & $149.79 \mathrm{e}$ & $1.04 \mathrm{pq}$ & $2713.20 \mathrm{yz}$ & $18.50 \mathrm{p}$ & $740.25 \mathrm{z}$ & $51.06 \mathrm{p}$ & $1.403 \mathrm{~m}$ & $40.39 \mathrm{i}$ & $0.567 \mathrm{~m}$ & $15.51 b$ & $0.088 n$ \\
\hline & \multirow{3}{*}{4} & Myogen & $130.52 \mathrm{~m}$ & $1.36 \mathrm{k}$ & $2877.84 \mathrm{v}$ & $19.90 \mathrm{i}$ & $853.40 \mathrm{p}$ & $63.72 \mathrm{hi}$ & 1.5761 & $39.51 \mathrm{jk}$ & 0.6231 & $15.07 \mathrm{c}$ & $0.093 \ln$ \\
\hline & & Isaanka & $139.72 \mathrm{~h}$ & $2.00 \mathrm{c}$ & $4194.87 a$ & $21.15 \mathrm{e}$ & $885.33 n$ & $75.57 \mathrm{a}$ & $1.770 \mathrm{jk}$ & $41.65 \mathrm{e}$ & $0.737 \mathrm{ij}$ & $13.74 \mathrm{e}$ & $0.101 \mathrm{hj}$ \\
\hline & & Ginmus & $152.46 \mathrm{~d}$ & $1.12 \mathrm{n}$ & $2825.51 x$ & $19.50 \mathrm{k}$ & $793.33 \mathrm{u}$ & $61.03 \mathrm{k}$ & 1.5701 & $39.47 \mathrm{jk}$ & 0.6191 & $16.27 \mathrm{a}$ & 0.100hk \\
\hline & \multirow{3}{*}{8} & Myogen & 133.13jl & $1.26 \mathrm{~m}$ & $2836.81 \mathrm{w}$ & $19.70 \mathrm{j}$ & $824.80 \mathrm{~s}$ & $57.29 \mathrm{~m}$ & 1.5431 & $39.62 \mathrm{jk}$ & 0.6111 & $15.73 b$ & $0.096 \mathrm{~km}$ \\
\hline & & Isaanka & $140.93 \mathrm{~h}$ & $1.42 \mathrm{j}$ & $3144.16 p$ & $20.50 \mathrm{~g}$ & 856.49 o & $65.23 f g$ & $1.753 \mathrm{k}$ & $40.74 \mathrm{gh}$ & $0.714 \mathrm{jk}$ & $14.19 d$ & $0.101 \mathrm{hk}$ \\
\hline & & Ginmus & $149.66 \mathrm{e}$ & $1.02 \mathrm{q}$ & $2764.47 \mathrm{z}$ & $19.16 \mathrm{~m}$ & $767.37 x$ & 55.36no & 1.5331 & $39.29 \mathrm{k}$ & $0.6021 \mathrm{~m}$ & $16.47 \mathrm{a}$ & 0.099j1 \\
\hline \multirow{9}{*}{6} & \multirow{3}{*}{0} & Myogen & $129.93 \mathrm{~m}$ & $1.74 \mathrm{i}$ & $3072.84 \mathrm{r}$ & $18.83 n$ & $778.13 \mathrm{v}$ & $56.29 n$ & $1.853 \mathrm{ik}$ & $41.29 f$ & $0.765 \mathrm{i}$ & $13.30 \mathrm{gh}$ & $0.101 \mathrm{gk}$ \\
\hline & & Isaanka & $139.26 \mathrm{~h}$ & $1.90 \mathrm{e}$ & $3723.16 \mathrm{~d}$ & $20.16 \mathrm{~h}$ & $827.20 \mathrm{r}$ & $61.63 \mathrm{k}$ & $2.050 \mathrm{~g}$ & $43.72 b$ & $0.896 \mathrm{~g}$ & $12.43 \mathrm{ij}$ & $0.111 \mathrm{f}$ \\
\hline & & Ginmus & $158.66 \mathrm{c}$ & 1.331 & $2930.23 u$ & $17.90 \mathrm{q}$ & 749.93y & $55.32 \mathrm{no}$ & $1.783 \mathrm{jk}$ & 41.57ef & $0.741 \mathrm{ij}$ & $13.45 \mathrm{fg}$ & $0.099 \mathrm{j} 1$ \\
\hline & \multirow{3}{*}{4} & Myogen & $132.79 \mathrm{kl}$ & $1.78 \mathrm{gh}$ & $3178.77 \mathrm{~m}$ & $21.10 \mathrm{e}$ & $935.51 \mathrm{j}$ & $66.03 \mathrm{f}$ & $1.870 \mathrm{ij}$ & $40.79 \mathrm{~g}$ & $0.762 \mathrm{i}$ & $13.59 \mathrm{ef}$ & 0.103gij \\
\hline & & Isaanka & $147.00 f$ & $1.90 \mathrm{e}$ & $3834.40 \mathrm{~b}$ & $21.90 \mathrm{a}$ & $1013.20 \mathrm{c}$ & $73.03 b$ & $2.236 \mathrm{f}$ & $42.46 \mathrm{~d}$ & $0.949 \mathrm{f}$ & $12.51 \mathrm{ij}$ & $0.118 \mathrm{e}$ \\
\hline & & Ginmus & $160.60 \mathrm{bc}$ & $1.09 \mathrm{o}$ & $2986.37 \mathrm{~s}$ & 18.750 & $893.67 \mathrm{~m}$ & $64.39 \mathrm{gh}$ & $1.833 \mathrm{jk}$ & $40.75 \mathrm{gh}$ & $0.747 \mathrm{ij}$ & $14.44 d$ & $0.107 \mathrm{fh}$ \\
\hline & \multirow{3}{*}{8} & Myogen & $134.46 \mathrm{ik}$ & $1.80 \mathrm{~g}$ & $3145.83 n$ & $20.50 \mathrm{~g}$ & $925.43 \mathrm{k}$ & $63.09 \mathrm{ij}$ & $1.853 \mathrm{ik}$ & $40.38 \mathrm{i}$ & $0.748 \mathrm{ij}$ & $14.28 \mathrm{~d}$ & $0.106 \mathrm{fi}$ \\
\hline & & Isaanka & $144.93 \mathrm{~g}$ & $1.87 \mathrm{f}$ & $3806.57 \mathrm{c}$ & $21.26 \mathrm{~d}$ & $947.43 \mathrm{i}$ & $68.64 \mathrm{e}$ & $2.160 \mathrm{f}$ & $41.45 \mathrm{ef}$ & $0.895 \mathrm{~g}$ & $13.23 \mathrm{gh}$ & $0.118 \mathrm{e}$ \\
\hline & & Ginmus & $159.86 b c$ & $1.06 \mathrm{p}$ & $2971.52 \mathrm{t}$ & $18.44 p$ & $819.85 \mathrm{t}$ & $61.39 \mathrm{k}$ & $1.776 \mathrm{jk}$ & $40.29 \mathrm{i}$ & $0.716 \mathrm{jk}$ & $15.11 \mathrm{c}$ & $0.108 f g$ \\
\hline
\end{tabular}


Mesopotamia J. of Agric.

Vol. (45) No. (1) 2017
ISSN: 2224 - 9796 (Online) ISSN: 1815 - 316 X (Print)

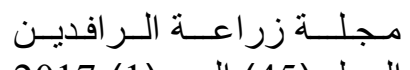
المجلد (45) العدد (1) 2017

\begin{tabular}{|c|c|c|c|c|c|c|c|c|c|c|c|c|c|}
\hline \multicolumn{2}{|c|}{$\begin{array}{c}\text { Application } \\
\left(\mathrm{mg} \cdot \mathrm{L}^{-1}\right)\end{array}$} & \multirow[t]{2}{*}{ genotypes } & \multirow{2}{*}{$\begin{array}{l}\text { plant } \\
\text { height } \\
(\mathrm{cm}) \\
\end{array}$} & \multirow{2}{*}{$\begin{array}{c}\text { stem } \\
\text { diameter } \\
(\mathrm{cm})\end{array}$} & \multirow[t]{2}{*}{$\begin{array}{l}\text { leaf area } \\
\left(\mathrm{cm}^{2} \text { plant }\right)\end{array}$} & \multirow{2}{*}{\begin{tabular}{|c|} 
head \\
diameter \\
$(\mathrm{cm})$
\end{tabular}} & \multirow[t]{2}{*}{$\begin{array}{c}\text { no. of } \\
\text { seeds/head }\end{array}$} & \multirow{2}{*}{$\begin{array}{c}1000 \\
\text { seeds } \\
\text { weight(g.) }\end{array}$} & \multirow{2}{*}{$\begin{array}{c}\text { yield } \\
\text { (ton.ha } \\
1 \text { ) }\end{array}$} & \multirow[t]{2}{*}{$\begin{array}{c}\text { oil } \\
(\%)\end{array}$} & \multirow{2}{*}{$\begin{array}{l}\text { oil yield } \\
\left.\text { (ton.ha }^{-1}\right)\end{array}$} & \multirow{2}{*}{$\begin{array}{l}\text { protein } \\
(\%)\end{array}$} & \multirow{2}{*}{$\begin{array}{c}\text { protein } \\
\text { yield } \\
\left(\text { ton.ha }^{-1}\right)\end{array}$} \\
\hline zinc & boron & & & & & & & & & & & & \\
\hline \multirow{9}{*}{12} & \multirow{3}{*}{0} & & $131.801 \mathrm{~m}$ & $1.94 \mathrm{~d}$ & $3281.55 \mathrm{j}$ & $20.80 \mathrm{f}$ & $983.08 \mathrm{f}$ & $61.26 \mathrm{k}$ & $1.973 \mathrm{gh}$ & $43.04 \mathrm{c}$ & $0.849 \mathrm{~h}$ & 11.541 & $0.098 \mathrm{j} 1$ \\
\hline & & Isaanka & $143.46 \mathrm{~g}$ & $2.06 \mathrm{~b}$ & $3507.90 \mathrm{~g}$ & $21.51 \mathrm{c}$ & $1015.00 \mathrm{~b}$ & $67.70 \mathrm{e}$ & $2.550 \mathrm{~cd}$ & $45.46 \mathrm{a}$ & $1.15 \pi$ & $10.71 \mathrm{~m}$ & $0.124 \mathrm{e}$ \\
\hline & & Ginmus & $161.06 \mathrm{~b}$ & $1.72 \mathrm{i}$ & $3145.04 \mathrm{o}$ & $19.90 \mathrm{i}$ & $854.62 p$ & 58.261 & 1.946hi & $42.63 d$ & $0.829 \mathrm{~h}$ & $12.25 \mathrm{j}$ & $0.101 \mathrm{gk}$ \\
\hline & \multirow{3}{*}{4} & Myogen & $135.86 \mathrm{i}$ & $2.02 \mathrm{c}$ & $3383.65 \mathrm{~h}$ & $20.78 \mathrm{f}$ & $1008.38 \mathrm{~d}$ & $69.70 \mathrm{~d}$ & $2.643 c$ & $41.44 \mathrm{ef}$ & $1.095 \mathrm{~d}$ & $12.57 \mathrm{i}$ & $0.137 \mathrm{~cd}$ \\
\hline & & Isaanka & $164.33 \mathrm{a}$ & $2.18 \mathrm{a}$ & $3586.84 \mathrm{e}$ & $21.56 \mathrm{c}$ & $1052.60 \mathrm{a}$ & $73.70 \mathrm{~b}$ & $3.190 \mathrm{a}$ & $45.18 \mathrm{a}$ & $1.441 \mathrm{a}$ & $11.91 \mathrm{k}$ & $0.171 \mathrm{a}$ \\
\hline & & Ginmus & $163.33 \mathrm{a}$ & $1.77 \mathrm{~h}$ & $3218.22 \mathrm{k}$ & $20.52 \mathrm{~g}$ & $949.39 \mathrm{~h}$ & 63.69hi & $2.506 \mathrm{~d}$ & $41.30 \mathrm{ef}$ & $1.035 \mathrm{e}$ & $13.11 \mathrm{~h}$ & $0.135 \mathrm{~cd}$ \\
\hline & & Myogen & $133.66 \mathrm{jl}$ & $2.00 \mathrm{c}$ & $3344.18 \mathrm{i}$ & $21.10 \mathrm{e}$ & $951.00 \mathrm{~g}$ & $68.36 \mathrm{e}$ & $2.560 \mathrm{~cd}$ & 41.31ef & $1.057 \mathrm{e}$ & $13.35 \mathrm{fh}$ & $0.141 \mathrm{c}$ \\
\hline & & Isaanka & $147.00 \mathrm{f}$ & $2.16 \mathrm{a}$ & $3533.88 f$ & $21.73 b$ & $1001.19 \mathrm{e}$ & $71.36 \mathrm{c}$ & $2.770 \mathrm{~b}$ & $43.55 b$ & $1.206 \mathrm{~b}$ & $12.43 \mathrm{ij}$ & $0.149 b$ \\
\hline & & Ginmus & $149.92 \mathrm{e}$ & $1.79 \mathrm{gh}$ & 3194.901 & $18.90 n$ & 912.351 & $62.70 \mathrm{j}$ & $2.410 \mathrm{e}$ & $0.959 f$ & $0.959 \mathrm{f}$ & $13.78 \mathrm{e}$ & $0.132 \mathrm{~d}$ \\
\hline
\end{tabular}

${ }^{*}$ The mean values within column followed by the different letters are significant at $5 \%$ level.

Table (9): Effect of interaction between zinc, boron foliar application and sunflower genotypes on some growth characters, yield components and quality in autumn seasons.

\begin{tabular}{|c|c|c|c|c|c|c|c|c|c|c|c|c|c|}
\hline \multicolumn{2}{|c|}{$\begin{array}{c}\text { Application } \\
\left(\mathrm{mg} . \mathrm{L}^{-1}\right)\end{array}$} & \multirow[t]{2}{*}{ genotypes } & \multirow{2}{*}{$\begin{array}{l}\text { plant } \\
\text { height } \\
(\mathrm{cm})\end{array}$} & \multirow{2}{*}{$\begin{array}{c}\text { stem } \\
\text { diameter } \\
(\mathrm{cm})\end{array}$} & \multirow[t]{2}{*}{$\begin{array}{l}\text { leaf area } \\
\left(\mathrm{cm}^{2} \text { plant }\right)\end{array}$} & \multirow{2}{*}{$\begin{array}{c}\text { head } \\
\text { diameter } \\
(\mathrm{cm})\end{array}$} & \multirow[t]{2}{*}{$\begin{array}{c}\text { no. of } \\
\text { seeds/head }\end{array}$} & \multirow{2}{*}{$\begin{array}{c}1000 \\
\text { seeds } \\
\text { weight }(\mathrm{g} .)\end{array}$} & \multirow{2}{*}{$\begin{array}{c}\text { yield } \\
\text { (ton.ha } \\
1 \\
\text { () }\end{array}$} & \multirow[t]{2}{*}{$\begin{array}{c}\text { oil } \\
(\%)\end{array}$} & \multirow[t]{2}{*}{$\begin{array}{l}\text { oil yield } \\
\text { (ton.ha }^{-1} \text { ) }\end{array}$} & \multirow[t]{2}{*}{$\begin{array}{l}\text { protein } \\
(\%)\end{array}$} & \multirow{2}{*}{$\begin{array}{c}\text { protein } \\
\text { yield } \\
\text { (ton.ha }^{-1} \text { ) }\end{array}$} \\
\hline zinc & boron & & & & & & & & & & & & \\
\hline & \multirow{3}{*}{0} & & 124.391 & $1.27 \mathrm{~m}$ & 274 & 19.31hi & 100. & $50.25 q$ & 1.4811 & 41.1 & & 13 & $0.203 \mathrm{kl}$ \\
\hline & & Isaa & $39.94 \mathrm{eh}$ & $1.66 \mathrm{ij}$ & 310 & $20.38 \mathrm{ef}$ & & $54.23 \mathrm{o}$ & $1.578 \mathrm{k}$ & 43. & & 12 & 0.1971 \\
\hline & & $\mathrm{Gi}$ & $41.34 \mathrm{dg}$ & $0.93 \mathrm{rs}$ & 272 & $18.34 \mathrm{k}$ & & $50.97 p$ & $1.358 \mathrm{~m}$ & 41. & & 14.82 & $0.202 \mathrm{kl}$ \\
\hline & & en & $128.96 \mathrm{kl}$ & $1.25 \mathrm{~m}$ & 28 & $19.74 \mathrm{gh}$ & 1. & 64.29hi & $1.531 \mathrm{kl}$ & 40 & 0 . & 14 & $0.221 \mathrm{ik}$ \\
\hline & & & $40.94 \mathrm{dg}$ & $1.92 \mathrm{~d}$ & 4 & $21.02 \mathrm{~cd}$ & 8 & $75.15 a$ & $1.725 \mathrm{j}$ & 42 & $\mathrm{~km}$ & 13 & $0.226 h j$ \\
\hline & & Ginmus & $146.23 \mathrm{dg}$ & $1.01 \mathrm{p}$ & 2802.510 & 19.34hi & 788.171 & $61.27 \mathrm{k}$ & $1.525 \mathrm{kl}$ & $40.19 \mathrm{v}$ & $0.612 \mathrm{o}$ & 15.42 & $0.236 \mathrm{fi}$ \\
\hline
\end{tabular}


Mesopotamia J. of Agric.

Vol. (45) No. (1) 2017
ISSN: 2224 - 9796 (Online)

ISSN: 1815 - 316 X (Print)

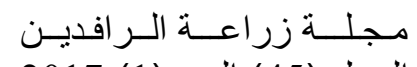
المجلد (45) العدد (1) 2017

\begin{tabular}{|c|c|c|c|c|c|c|c|c|c|c|c|c|c|}
\hline \multicolumn{2}{|c|}{$\begin{array}{l}\text { Application } \\
\left(\mathrm{mg} \cdot \mathrm{L}^{-1}\right)\end{array}$} & \multirow[t]{2}{*}{ genotypes } & \multirow{2}{*}{$\begin{array}{l}\text { plant } \\
\text { height } \\
(\mathrm{cm})\end{array}$} & \multirow{2}{*}{$\begin{array}{c}\text { stem } \\
\text { diameter } \\
(\mathrm{cm})\end{array}$} & \multirow{2}{*}{$\begin{array}{c}\text { leaf area } \\
\left(\mathrm{cm}^{2} \text { plant }\right)\end{array}$} & \multirow{2}{*}{$\begin{array}{c}\text { head } \\
\text { diameter } \\
(\mathrm{cm})\end{array}$} & \multirow{2}{*}{$\begin{array}{c}\text { no. of } \\
\text { seeds/head }\end{array}$} & \multirow{2}{*}{$\begin{array}{r}1000 \\
\text { seeds } \\
\text { weight(g.) } \\
\end{array}$} & \multirow{2}{*}{$\begin{array}{c}\text { yield } \\
\text { (ton.ha } \\
{ }^{1} \text { ) }\end{array}$} & \multirow{2}{*}{$\begin{array}{c}\text { oil } \\
(\%)\end{array}$} & \multirow{2}{*}{$\begin{array}{c}\text { oil yield } \\
\left(\text { ton.ha }^{-1}\right)\end{array}$} & \multirow{2}{*}{$\begin{array}{l}\text { protein } \\
(\%)\end{array}$} & \multirow{2}{*}{$\begin{array}{c}\text { protein } \\
\text { yield } \\
\left.\text { (ton.ha }^{-1}\right)\end{array}$} \\
\hline zinc & boron & & & & & & & & & & & & \\
\hline & \multirow{3}{*}{0} & Myogen & $130.68 \mathrm{il}$ & 1.150 & $2813.82 \mathrm{o}$ & $19.54 \mathrm{gh}$ & $819.64 k$ & $56.87 \mathrm{~m}$ & 1.4981 & $40.34 \mathrm{t}$ & $0.603 \mathrm{o}$ & 14.71 & $0.221 \mathrm{ik}$ \\
\hline & & Isaanka & $138.93 \mathrm{fi}$ & 1.311 & $3121.16 \mathrm{j}$ & $20.34 \mathrm{ef}$ & $851.34 \mathrm{j}$ & $64.80 \mathrm{~h}$ & $1.708 \mathrm{j}$ & 41.460 & $0.707 \mathrm{mn}$ & 13.17 & $.226 h j$ \\
\hline & & Gin & 147.44ce & $0.92 \mathrm{~s}$ & $2742.32 \mathrm{p}$ & $19.00 \mathrm{ij}$ & $762.21 \mathrm{n}$ & 54.910 & 1.4881 & $40.01 \mathrm{w}$ & $0.594 \mathrm{o}$ & 15.79 & $236 \mathrm{fi}$ \\
\hline \multirow{9}{*}{6} & \multirow{3}{*}{0} & en & $27.37 \mathrm{kl}$ & $1.63 \mathrm{k}$ & 30 & $18.67 \mathrm{jk}$ & $772.97 \mathrm{~m}$ & $55.87 \mathrm{n}$ & $1.821 \mathrm{i}$ & $42.01 \mathrm{~m}$ & $0.764 \mathrm{i}$ & 12.28 & $24 \mathrm{hj}$ \\
\hline & & Isa & $137.04 \mathrm{gj}$ & $1.79 \mathrm{~g}$ & 37 & $20.00 \mathrm{fg}$ & $4 \mathrm{k}$ & $61.21 \mathrm{k}$ & $2.018 \mathrm{~h}$ & $44.44 \mathrm{c}$ & $6 \mathrm{~g}$ & 11.41 & $31 \mathrm{gj}$ \\
\hline & & Gin & $0 a b$ & $1.22 \mathrm{n}$ & $3 \mathrm{~m}$ & 17.741 & $744.77 \mathrm{o}$ & $54.90 \mathrm{o}$ & $1.741 \mathrm{j}$ & $42.29 \mathrm{j}$ & $36 \mathrm{jl}$ & 12.43 & $17 \mathrm{ik}$ \\
\hline & \multirow{3}{*}{4} & Myogen & $131.01 \mathrm{jl}$ & $1.67 \mathrm{ij}$ & 3155.77hi & $20.97 \mathrm{~cd}$ & $930.35 \mathrm{~g}$ & $65.60 \mathrm{~g}$ & $1.832 \mathrm{i}$ & $41.51 \mathrm{n}$ & $0.759 \mathrm{ij}$ & 12.57 & $31 \mathrm{gj}$ \\
\hline & & Isaanka & $48.00 \mathrm{~cd}$ & $1.79 \mathrm{~g}$ & $3811.41 \mathrm{~b}$ & $21.74 \mathrm{ab}$ & $1008.04 b$ & $72.60 \mathrm{c}$ & $2.211 \mathrm{f}$ & $43.18 \mathrm{~h}$ & $0.954 \mathrm{f}$ & 11.49 & $5 \mathrm{df}$ \\
\hline & & Gi1 & $158.60 \mathrm{a}$ & $0.97 \mathrm{q}$ & 290 & $18.59 \mathrm{jk}$ & 88 & $63.97 i$ & $1.808 \mathrm{i}$ & $41.47 \mathrm{o}$ & $9 \mathrm{ik}$ & 13.42 & 3eh \\
\hline & \multirow{3}{*}{8} & Myogen & $32.57 \mathrm{hk}$ & $1.69 \mathrm{i}$ & $3122.83 \mathrm{j}$ & $20.34 \mathrm{ef}$ & $27 \mathrm{~h}$ & $62.67 \mathrm{j}$ & $1.821 \mathrm{i}$ & $41.10 \mathrm{q}$ & $8 \mathrm{ik}$ & 13.59 & $0.249 \mathrm{eg}$ \\
\hline & & Isaanka & $149.48 b c$ & $1.76 \mathrm{~h}$ & $3783.57 \mathrm{~b}$ & $21.10 \mathrm{~cd}$ & $942.27 f$ & $68.22 \mathrm{f}$ & $2.125 \mathrm{~g}$ & $42.17 \mathrm{k}$ & $0.895 \mathrm{~g}$ & 12.54 & $0.267 \mathrm{~d}$ \\
\hline & & uus & $57.75 \mathrm{a}$ & $0.95 \mathrm{qr}$ & 521 & $18.21 \mathrm{k}$ & $81^{\prime}$ & $60.97 \mathrm{k}$ & $1.738 \mathrm{j}$ & $41.01 \mathrm{y}$ & $21 \mathrm{~m}$ & 14.75 & $57 \mathrm{de}$ \\
\hline \multirow{9}{*}{12} & \multirow{3}{*}{0} & Myogen & $29.80 \mathrm{j} 1$ & $1.83 \mathrm{f}$ & $55 \mathrm{~g}$ & $20.31 \mathrm{ef}$ & $977.92 d$ & $61.17 \mathrm{k}$ & $1.995 \mathrm{~h}$ & $43.76 \mathrm{e}$ & $0.872 \mathrm{gh}$ & 10.52 & $0.211 \mathrm{jl}$ \\
\hline & & Isaanka & $148.24 \mathrm{~cd}$ & $1.95 \mathrm{c}$ & $3488.23 \mathrm{e}$ & $21.35 b c$ & $1009.84 b$ & $67.61 \mathrm{f}$ & $2.538 \mathrm{~d}$ & $46.18 \mathrm{a}$ & $1.171 \mathrm{c}$ & 9.69 & $0.247 \mathrm{eg}$ \\
\hline & & Ginmus & $159.06 a$ & $1.61 \mathrm{k}$ & $3125.38 \mathrm{ij}$ & $19.74 \mathrm{gh}$ & $849.46 \mathrm{j}$ & 58.171 & $1.968 \mathrm{~h}$ & $43.35 \mathrm{~g}$ & $0.852 \mathrm{~h}$ & 11.23 & $0.222 \mathrm{ij}$ \\
\hline & \multirow{3}{*}{4} & Myogen & $133.97 \mathrm{gk}$ & $1.91 \mathrm{de}$ & $3360.65 f$ & $20.62 \mathrm{de}$ & $1003.22 b c$ & $69.61 \mathrm{e}$ & $2.631 \mathrm{c}$ & $42.16 \mathrm{k}$ & $1.108 \mathrm{~d}$ & 11.55 & $.305 c$ \\
\hline & & Isaanka & $162.66 \mathrm{a}$ & $2.10 \mathrm{a}$ & $3563.84 d$ & $21.40 \mathrm{bc}$ & $1054.11 \mathrm{a}$ & $73.61 b$ & $3.178 \mathrm{a}$ & 45.90b & $1.458 \mathrm{a}$ & 10.89 & $0.347 \mathrm{a}$ \\
\hline & & Ginmus & $161.22 \mathrm{a}$ & $1.66 \mathrm{j}$ & $3228.55 \mathrm{~g}$ & $20.36 \mathrm{ef}$ & $950.90 \mathrm{ef}$ & $63.60 \mathrm{i}$ & $2.495 d$ & $42.021 \mathrm{~m}$ & $1.047 \mathrm{e}$ & 12.09 & $0.302 c$ \\
\hline & \multirow{3}{*}{8} & Myogen & 131.77il & $1.89 \mathrm{e}$ & $3334.51 \mathrm{f}$ & $20.94 \mathrm{~cd}$ & $955.84 \mathrm{e}$ & $68.27 f$ & $2.548 \mathrm{~d}$ & 42.031 & $1.070 \mathrm{e}$ & 12.66 & $0.324 b$ \\
\hline & & & $150.00 \mathrm{bc}$ & $2.05 \mathrm{~b}$ & $3510.88 \mathrm{e}$ & $21.90 \mathrm{a}$ & $996.03 \mathrm{c}$ & $71.27 \mathrm{~d}$ & $2.725 \mathrm{~b}$ & $44.27 \mathrm{~d}$ & $1.205 b$ & 11.74 & $0.321 b c$ \\
\hline & & Ginmus & $144.81 \mathrm{cf}$ & $1.68 \mathrm{ij}$ & $3171.91 \mathrm{~h}$ & 19.41hi & 917.19h & $62.61 \mathrm{j}$ & $2.414 \mathrm{e}$ & $40.45 \mathrm{~s}$ & $0.975 \mathrm{f}$ & 13.08 & $0.317 \mathrm{bc}$ \\
\hline
\end{tabular}

${ }^{*}$ The mean values within column followed by the different letters are significant at $5 \%$ level. 
Mesopotamia J. of Agric.

Vol. (45) No. (1) 2017
ISSN: $2224-9796$ (Online)

ISSN: 1815 - 316 X (Print)

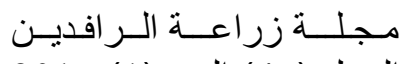
المجلد (45) العدد (1) 2017

Table (10): Analysis of variance F values for some growth characters, yield and yield components and quality in spring and autumn seasons.

\begin{tabular}{|c|c|c|c|c|c|c|c|c|c|c|c|c|}
\hline \multirow[b]{2}{*}{ S.O.V } & \multirow[b]{2}{*}{ D.f } & \multicolumn{11}{|c|}{ M.S. for spring season } \\
\hline & & $\begin{array}{l}\text { plant } \\
\text { height } \\
(\mathrm{cm})\end{array}$ & $\begin{array}{c}\text { stem } \\
\text { diameter } \\
(\mathrm{cm})\end{array}$ & $\begin{array}{c}\text { leaf area } \\
\left(\mathrm{cm}^{2} \backslash \text { plant }\right)\end{array}$ & $\begin{array}{c}\text { head } \\
\text { diameter } \\
(\mathrm{cm})\end{array}$ & $\begin{array}{c}\text { no. of } \\
\text { seeds/head }\end{array}$ & $\begin{array}{c}1000 \\
\text { seeds } \\
\text { weight }(\mathrm{g} .)\end{array}$ & $\begin{array}{c}\text { yield } \\
\left(\text { ton.ha }^{-1}\right)\end{array}$ & $\begin{array}{l}\text { oil } \\
(\%)\end{array}$ & $\begin{array}{l}\text { oil yield } \\
\text { (ton.ha }^{-1} \text { ) }\end{array}$ & $\begin{array}{l}\text { protein } \\
(\%)\end{array}$ & $\begin{array}{c}\text { protein } \\
\text { yield } \\
\text { (ton.ha }{ }^{-1} \text { ) }\end{array}$ \\
\hline Replications & 2 & 36.012346 & 0.00029259 & 0.001 & 0.0042259 & 0.3929 & 0.3712 & 0.00199 & 0.50644 & 0.00060 & 0.0238 & 0.000018 \\
\hline A & 2 & $470.2353 * *$ & $2.341559 * *$ & $831976.7 * *$ & 7.55727 & $167034.10 * *$ & $323.53 * *$ & $5.7947 * *$ & $32.726 * *$ & $1.2604 * *$ & $43.314 * *$ & $0.00947 * *$ \\
\hline B & 2 & $229.7648 * *$ & $0.058581 * *$ & $302543.2 * *$ & $4.87290 * *$ & $58595.77 * *$ & $746.55^{* *}$ & $0.5342 * *$ & $18.708 * *$ & $0.0667 * *$ & $11.893^{* *}$ & $0.00281 * *$ \\
\hline $\mathrm{C}$ & 2 & $3943.471 * *$ & $2.411433 * *$ & $3009271.8 * *$ & $29.4608 * *$ & $75483.29 * *$ & $539.36 * *$ & $1.0453 * *$ & $46.500 * *$ & $0.3364 * *$ & $21.805 * *$ & $0.00154 * *$ \\
\hline$A \times B$ & 4 & $90.6978 * *$ & $0.064307 * *$ & $123599.1 * *$ & $1.38072 * *$ & $10347.06^{* *}$ & $39.78 * *$ & $0.2155^{* *}$ & $0.5950 * *$ & $0.0365 * *$ & $0.297 * *$ & $0.00088^{* *} *$ \\
\hline $\mathrm{A} \times \mathrm{C}$ & 4 & $82.3129 * *$ & $0.156287 * *$ & $194304.6 * *$ & $1.07049 * *$ & $586.093 * *$ & $12.38 * *$ & $0.0723 * *$ & $2.2315 * *$ & $0.029 * *$ & $0.659 * *$ & $0.00034 * *$ \\
\hline $\mathrm{B} \times \mathrm{C}$ & 4 & $87.7920 * *$ & $0.027525 * *$ & $115289.1 * *$ & $0.32599 * *$ & $204.252 * *$ & $12.73 * *$ & $0.0108 * *$ & $0.7458 * *$ & $0.004 * *$ & $0.0589 *$ & $0.000061 * *$ \\
\hline $\mathrm{A} \times \mathrm{B} \times \mathrm{C}$ & 8 & $24.8668 * *$ & $0.030140 * *$ & $107462.3 * *$ & $0.56971 * *$ & $1781.679 * *$ & $7.852 * *$ & $0.0188 * *$ & $0.3987 * *$ & $0.003 * *$ & $0.124 * *$ & $0.000052 * *$ \\
\hline Error & 52 & 1.43542 & 0.0001669 & 0.01 & 0.0019605 & 0.5648 & 0.31774 & 0.00294 & 0.03730 & 0.00052 & 0.02295 & 0.0000122 \\
\hline Total & 80 & & & & & & & & & & & \\
\hline S.O.V & D.f & \multicolumn{11}{|c|}{ M.S. for autumn season } \\
\hline Replications & 2 & 144.294734 & 0.94792119 & 52857.281 & 2.4386096 & 3104.9623 & 23.5968 & 0.24340 & 42.0336 & 0.00878 & 99.9594 & 0.0644507 \\
\hline A & 2 & $604.0933 * *$ & $2.334880 * *$ & $812396.9 * *$ & $8.70827 * *$ & $173154.15 * *$ & $332.71 * *$ & $6.2905 * *$ & $32.875 * *$ & $1.3940 * *$ & $47.979 * *$ & $0.034348 * *$ \\
\hline $\mathrm{B}$ & 2 & $196.2529 * *$ & $0.065017 * *$ & $294486.7 * *$ & $5.36763 * *$ & $61056.07 * *$ & $765.48 * *$ & $0.5081 * *$ & $18.624 * *$ & $0.0668 * *$ & $15.379 * *$ & $0.021457 * *$ \\
\hline $\mathrm{C}$ & 2 & $3612.997 * *$ & $2.473979 * *$ & $2992165.4 * *$ & $28.6054 * *$ & $73005.13 * *$ & $524.92 * *$ & $1.0053 * *$ & $46.371 * *$ & $0.3330 * *$ & $23.041 * *$ & $0.001412 * *$ \\
\hline$A \times B$ & 4 & $104.2184 * *$ & $0.067798 * *$ & $113856.8 * *$ & $1.09871 * *$ & $9626.48 * *$ & $45.490 * *$ & $0.1931 * *$ & $0.5735 * *$ & $0.0340 * *$ & $0.9015 * *$ & $0.004499 * *$ \\
\hline $\mathrm{A} \times \mathrm{C}$ & 4 & $127.9765 * *$ & $0.159171 * *$ & $203746.2 * *$ & $1.18666 * *$ & $503.34 * *$ & $11.270 * *$ & $0.0612 * *$ & $2.1936 * *$ & $0.0266 * *$ & $0.7011 * *$ & $0.000650 * *$ \\
\hline $\mathrm{B} \times \mathrm{C}$ & 4 & $49.440590 *$ & $0.035110 * *$ & $110751.7 * *$ & $0.2046^{*}$ & $272.07 * *$ & $12.044 * *$ & $0.0139 * *$ & $0.7403 * *$ & $0.0050 * *$ & $0.095^{\mathrm{ns}}$ & $0.000213^{\mathrm{ns}}$ \\
\hline $\mathrm{A} \times \mathrm{B} \times \mathrm{C}$ & 8 & $41.130801 *$ & $0.031339 * *$ & $107302.7 * *$ & $0.44575 * *$ & $1878.96 * *$ & $7.2241 * *$ & $0.0200 * *$ & $0.3851 * *$ & $0.0036 * *$ & $0.152^{\mathrm{ns}}$ & $0.0002520 *$ \\
\hline Error & 52 & 16.71689 & 0.00025303 & 345.32 & 0.0756278 & 31.6701 & 0.188265 & 0.001155 & 0.000075 & 0.000201 & 0.108740 & 0.00011201 \\
\hline Total & 80 & & & & & & & & & & & \\
\hline
\end{tabular}

*,** Significant at the 0.05 and 0.01 probability levels, respectively. and n.s. not significant. 
Vannozzi, et al. (1988); Faizani et al. (1990); Prasad, (1991); Villalobos et al. (1994); Herdem, (1999); Castro et al, (2000) and Nel, (2001). It could be concluded that maximizing seed and oil yields per unit area could be achieved by sowing sunflower Issanka genotype with adding zinc dose of $12 \mathrm{mg}$. $\mathrm{L}^{-1}$ and boron with concentration of $4 \mathrm{mg} . \mathrm{L}^{-1}$ under the environmental conditions of the west north region of Mosul city at Nineveh Governorate.

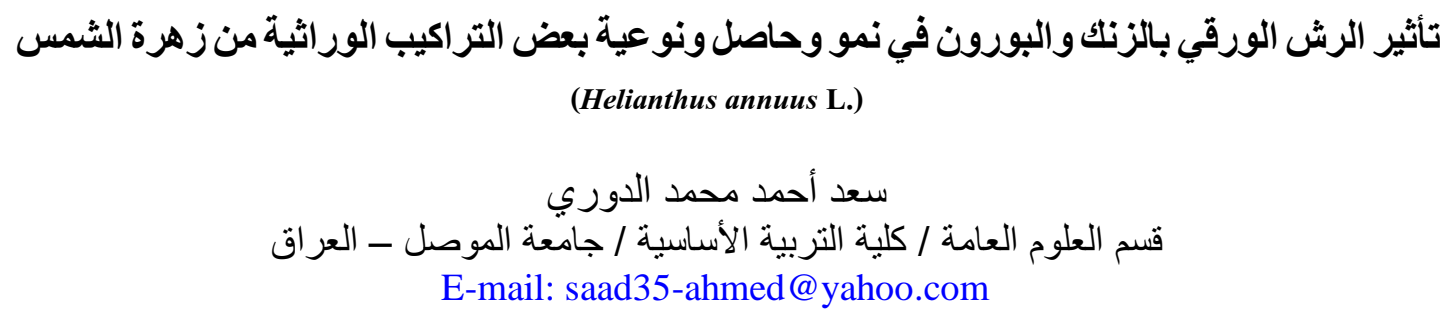

\section{الخلاصة}

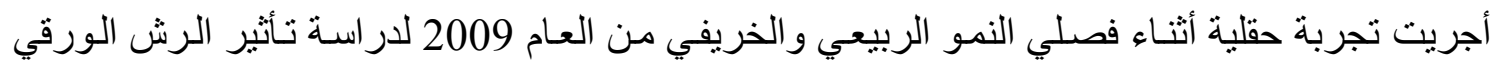

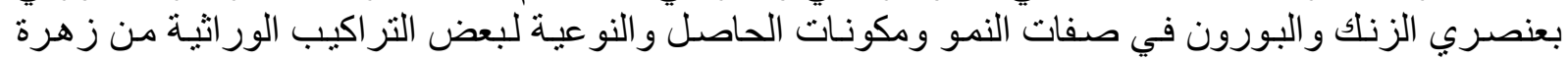

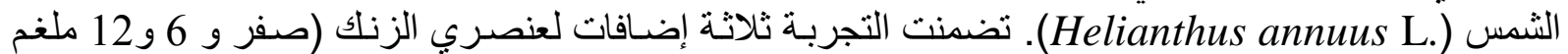

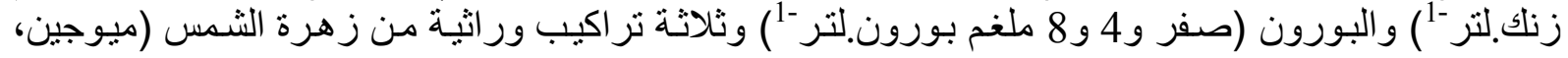
اسنكا وجنمس) نفذت وفق نظام التجارب العاملية بتصميم القطاعات العشو ائية الكاملة.

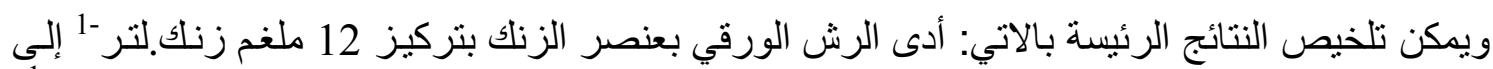

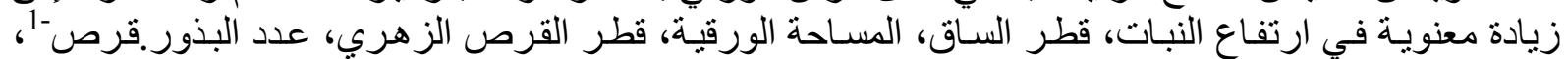

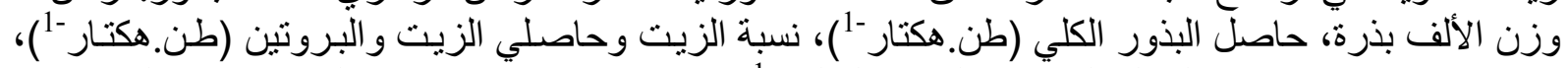

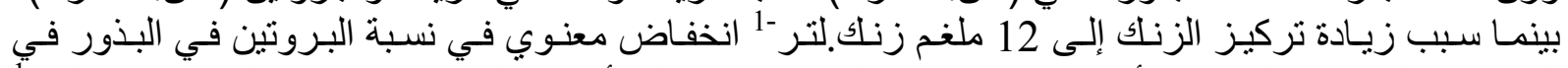

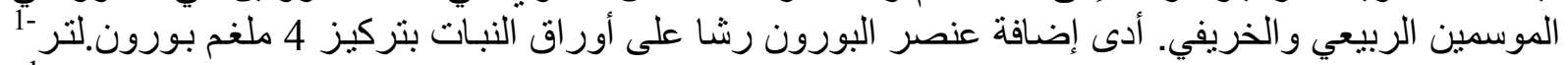

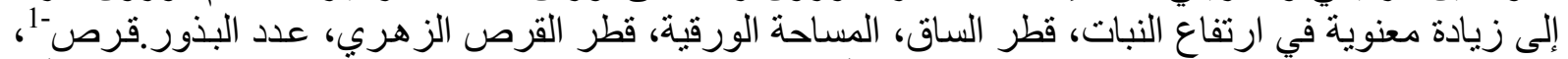

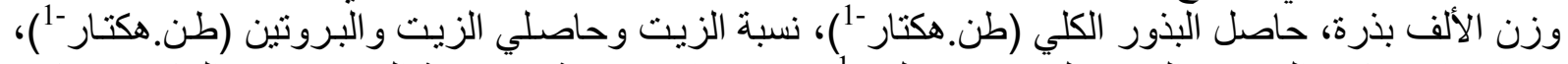

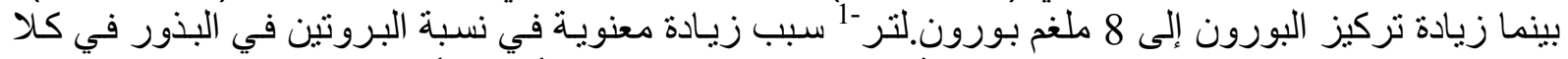

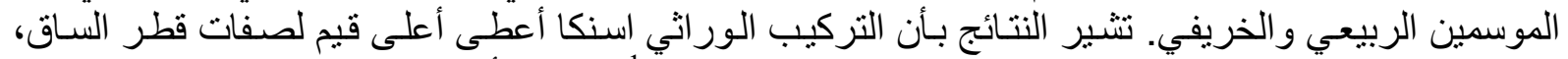

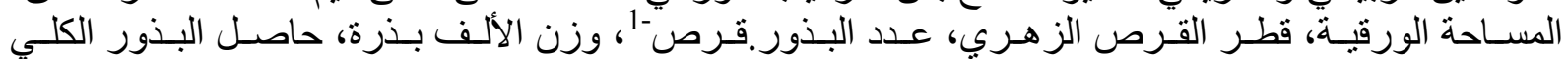

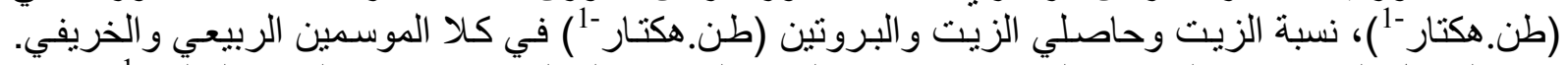

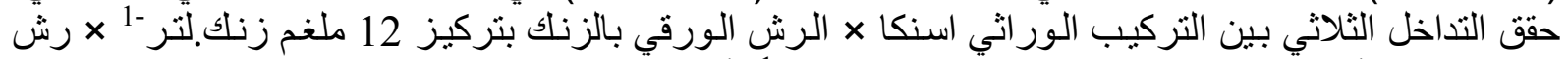

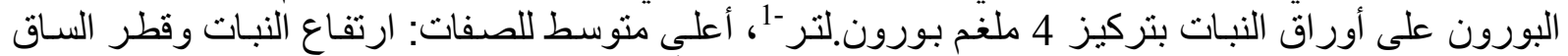

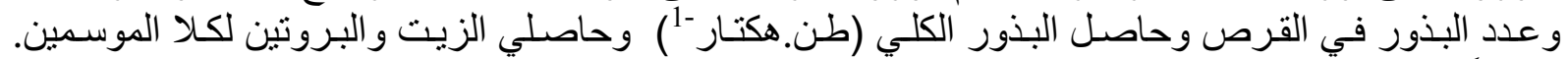

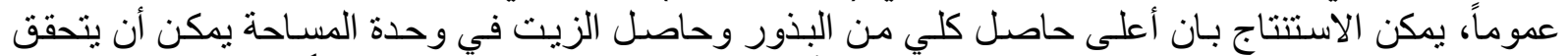

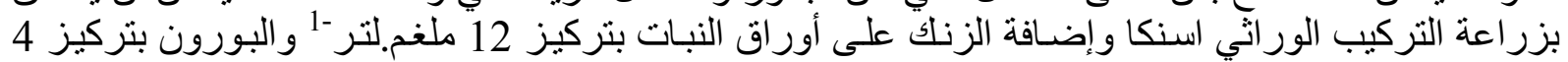
ملغم.لتر -1 تحت الظروف البت البيئية لهذه الدر اسنة.

الكلمات الدالة: الرش بالزنك و البورون، تر اكيب وراثية من زهرة الثمس .Helianthus annuus L. تاريخ تسلم البحث: 2012/7/1 ، وقبوله: 2013/3/18.

\section{REFERENCES}

Agrawal, S. C.; M. S., Jolly and A. M., Sinha (1980). Foliar constituents of secondary food plants of tasar silk Antheraea mylitta. Journal of Indian Forest, 106 (12): $847-851$. 
Anonymous, (1980). Official Methods of Analysis. Association of Official Analytical Chemists. Washington, U.S.A.

Anonymous, (1998). Standard Methods For The Examination Of Water And Waste Water. American Public Health Association (20 ${ }^{\text {th }}$ Eds.). Washington D.C., U.S.A.

Anonymous, (2001). Statistical Analysis Systems. SAS Institute Inc., Cary, NC, USA.

Asad, A.; F. P. C., Blamey and D.G., Edward (2002). Effects of boron foliar application on vegetative and reproduction growth of sunflower. Annals of Botany 92: 1 - 6.

Baldini, M. and G. P., Vannozzi (1999). Yield relationships under drought In Sunflower genotypes obtained from a wild population and cultivated Sunflowers in rainout shelter in large pots and field experiments. Helia 22: 8196.

Baldini, M. and G. P., Vear (1994). Crop management practices and environmental effects on hullability in Sunflower hybrids. Helia 19: 47-62.

Beyersmann, D. and H., Haase (2002). Function of zinc in signaling profilation and diffretiation of mamalian cells biometals. Clinical and Experimental Metastasis Journal 14 (3-4): 331-341.

Black, C. A. (1965). Methods Of Soil Analysis. Part 2. Chemical and Microbiological Properties. American Society of Agronomy. Inc. Publisher Madison. USA.

Blamey, F. P. C. and J., Chapman (1982). Protein, oil, and energy yields of Sunflower as affected by $\mathrm{N}$ and $\mathrm{P}$ fertilization. Agronomy Journal 73: 583-587.

Castro, C.; A., Moreira and J. B. R., Abreu (2000). Sunflower response to water stress and boron application. 15 International Sunflower Conference. Toulouse. France. Tome. 1: 145 - 149.

Chhotu, D. Jadia, Madhusudanh and N., Fulekar (2008). The Application of vermic compost to remove zinc, cadmium, copper, nickel and lead by Sunflower Plant. Journal of Environmental Biota and Management 7-5: 547-558.

Cui, Y.; Q. Wang and P. Christie (2004). Effect of elemental sulphur on uptake of Cadmium, Zinc, and Sulphur by Sunflower growing in soil contaminated with zinc and cadmium. Soil Science and Plant Analysis Journal, 35: 2905-2916.

Dedio, W. (1985). Effects of seeding and harvesting dates on yield and oil quality of Sunflower cultivars. Canadian Journal of Plant Science, 65: 299-305.

Duncan, B.O. (1955). Multiple range and multiple F test. Biometrics 11:1- 42.

Faizani, K. G. M.; V., Satyanarayana; A., Latchanna; M., Shaik and N. V., Ramaiah (1990). Response of Sunflower genotypes (Helianthus annuus L.) to nitrogen levels. Journal Research. APAU, 18(1): 57-59.

Farah, M. A.; M. F., Soliman; H. K., Bakhati and I. M., Antar (1981). On the response of two Sunflower varieties to nitrogen and phosphorus fertilization under saline conditions. Agricultural Research Journal, 59: 143-155. 
Frey, B.; C., Keller; K., Zierold; R., Shulin (2006). Distribution of zinc in function allay different leaf epidermal cells of hyperaccumulator. Plant Cell and Environment Journal 23: 675-687.

Gimenez, C. and E. Fereres (1987). Drought resistance in Sunflower cultivars under field conditions. Investigacion Agraria, Production grain filling in sunflower: the effect of water stress. Plant and Soil Journal, 121(1): 57-66.

Gitte, A.N.; S. R. Patil; M. A. Tike (2005). Influence of zinc and boron biochemical and yield characteristics of sunflower. Journal of Plant Physiology.10 (4): 431 438.

Harris, H.C. and B.B., John (1996). Comparison of Ca and boron deficiencies of plant. I physiological and yield deficiencies. Agronomy Journal 58 (1): 575- 578.

Herdem, E. (1999). Effect of Nitrogen Levels on Yield and Yield Components of Some Sunflower Genotypes. M. Sc. Thesis. Field Crops Department, Agriculture Collage, Trakya Univ., Tekirdag, Turkey.

Hilton, B. R. and J. C., Zubriski (1985). Effects of Sulfur, Zinc, Iron, Copper, Manganese, and Boron Applications on Sunflower Yield and Plant Nutrient Concentration. Commun. Soil Science Plant Analysis Journal 16: 411-425.

Iskander, F. Y. (1993). Determination of seventeen elements in edible oils and margarine by instrumental neutron activation analysis. Journal of the American Oil Chemists Society 70: 803- 805.

Jackson, M. L. (1973). Soil Chemical Analysis. Prentice Hall of India Pvt, New Delhi.

Kalarani, M. K; A. Senthit and M., Thangarj (2004). Effect of water stress on morph physiological traits of Sunflower (Helianthus annuus L.) genotypes. Madras Journal of Agriculture, 91( 4-6): 239-248.

Kathirresan, G.; S. S. Pannar and M. D., Seikh (2001). Effect of zinc deficiency in Sunflower . India Journal of Science Technology, 29: 1-2.

Khurana, N. and C. Chatterjee (2001). Influence of variable zinc on yield, oil content and Physiology of sunflower. Soil Science and Plant Analysis Journal 32: 3023-3030.

Korenovska, M. and O., Polacekova (2000). Trace elements content in virgin Sunflower oil production. Czech Journal of Food Science 18: 61-65.

Lindsay, W. L. (1996). Zinc Soil and Plant. Nutrition. Advances in Agronomy Journal , 24:147-186.

Luan, C. M. (2006). Evaluating the influence of seeding dates on yield and quality of different Sunflower varieties. Journal of Agriculture Research:1-5, Pakistan.

Maas, E.V. (1990). Boron Tolerance Limits For Agriculture Crops. United States. Salinity Laboratory.

Mariayesa, I. O.; S. O., Agele and I. A., Adeniji (2007). Effect of variety and row spacing on radiation interception, partitioning of dry matter and seed set efficiency in late season Sunflower (Helianthus annuиs L.) in Ahumid zone of Nigeria. African. Journal of Agriculture Research 293: 80- 88. 
Marie, T. and E., Howarth (2009). Plant breeding term strategy for the control of Zinc deficiency in vulnerable population. Journal of Plant Nutrient. 9: 70-77.

Martin, B; R. Philip; W. J., Hammond; P. Ivan and A. Lux (2007). Zinc in plant. Journal of Plant Philologist. 173: 677 -702.

Meszaros, G. and K., Simits (1992). Effect of Leaf Nutrition at Different Stages of Development on Achene and oil Yield of Sunflower. Helia 15: 9-16.

Milutinoc, and D. Stanojevic (1988). Effective of Zn and B on Seed yield, oil content and morphological traits of sunflower. Journal of Agriculture and Technology Research 142: 33- 39.

Mirzapour, M. and A., Khoshgoftar (2006). Zinc application effect on yield and seed oil content of Sunflower grown on a saline calcareous soil. Journal of Plant Nutrient. 29 (10): 1719 -1727.

Moore, H. M. and A.M., Hirsch (1983). Effects of boron deficiency on mitosis and incorporation of tritiated thymidine into nuclei of Sunflower root tips. American Journal of Botany. 70(2): 165-172.

Nel, A. A. (2001). Determinations of Sunflower Seed Quality for Processing. Ph. D. Thesis, Faculty of Natural and Agriculture Science Univ. of Pretoria, Pretoria.

Nel, A. A.; H. L., Loubser and P.S., Hammes (2000). The Effect of Environment and Cultivar on Sunflower Seed. I. Yield, Hullability and Physical Seed Characteristics. South Africa Journal of Plant Soil 17: 133-137.

Oyinlola, E.Y. (2007). Effect of boron fertilizer on yield and oil content of three Sunflower cultivars in the Nigerian savanna. Journal of Agriculture. 6 (3): 421 426.

Page, A. L.; R. H., Miller and D. R., Kenney (1982). Methods of Soil Analysis. Part (2) Agronomy no. 9 Madison. USA.

Prasad, (1991). Development of drought tolerant Sunflower for semiarid tracts of India: duration of genotypes influence their performance under imposed moisture stress. Helia. 14(1): 77-85.

Rani, P. L. and T. M. M., Reddy (1993). Effect of nitrogen and boron on yield components, yield and oil content of Sunflower (Helianthus annuus L.). Journal of Research. APAU. 21 (1/2): 39 - 41.

Remussi, C.; H., Saumell and G. A., Vidal Aponte (1972). Vegetative Growth, Yield and Industrial Quality of Three Sunflower Cultivars as Influenced by Different Dates of Planting. P. 137-144. In 5o Conference Internationale Sur Le Tournesol, Clermont-Ferrand. 25-29 July 1972. International Sunflower Association. Paris, France.

Sharma, C. P. (2006). Zinc nitrites and plant growth. En field, NH, USA Science Publishers.

Sharma, K. R.; P. C., Srivastara; D., Ghosh and M.S., Gangwar (1999). Effect of boron and farmyard manure application on growth, yield and boron nutrition of sunflower. Journal of Plant Nutrent. 22 (4 and 5): 633-640. 
Tahsin, T. N. and B.,Yankov (2007). Research on Accumulation of Zinc (Zn) and Cadmium (Cd) in Sunflower Oil. Tekirdag Ziraat Faculties Dergisi. Journal of Tekirdag Agriculture Faculty 4(1): 109-112

Tandon, H. (1999). Methods of Analysis of Soil, Plants, Water and Fertilizers. Fertilizer Development and Consultation Organization, New Delhi, India, pp: 144.

Vannozzi, G.P.; M., Baldini and A., Benvenuti, (1988). The responses of Sunflower cultivar, sown late in the season, to different irrigation regimes. Sementi Elette, 34(1): 19-23.

Villalobos, F. J.; V.O., Sadras; A., Soriano and E., Fereres (1994). Planting Density Effects on Dry Matter Partitioning and Productivity of Sunflower Hybrids. Journal of Field Crops Research 36: 1-11.

Zehra, E.; T. Murat and Y., Ibrahim (2007). Evaluation of seed oil yields and yield properties of different sunflowers hybrids varieties in Van, Turkey. Journal of Biological Science 8 (5): 683 -686. 